\title{
Homogeneous Catalyzed Valorization of Furanics: A Sustainable Bridge to Fuels and Chemicals
}

\author{
Rosa Padilla *(D), Sakhitha Koranchalil *(D) and Martin Nielsen (D) \\ Department of Chemistry, Technical University of Denmark, DK-2800 Kongens Lyngby, Denmark; \\ marnie@kemi.dtu.dk \\ * Correspondence: rmar@kemi.dtu.dk (R.P.); sakk@kemi.dtu.dk (S.K.)
}

\begin{abstract}
The development of efficient biomass valorization is imperative for the future sustainable production of chemicals and fuels. Particularly, the last decade has witnessed the development of a plethora of effective and selective transformations of bio-based furanics using homogeneous organometallic catalysis under mild conditions. In this review, we describe some of the advances regarding the conversion of target furanics into value chemicals, monomers for high-performance polymers and materials, and pharmaceutical key intermediates using homogeneous catalysis. Finally, the incorporation of furanic skeletons into complex chemical architectures by multifunctionalization routes is also described.
\end{abstract}

Keywords: furanics; homogeneous catalysis; biomass upgrading

check for updates

Citation: Padilla, R.; Koranchalil, S.; Nielsen, M. Homogeneous Catalyzed Valorization of Furanics: A Sustainable Bridge to Fuels and Chemicals. Catalysts 2021, 11, 1371. https://doi.org/10.3390/catal11111371

Academic Editors: Leonarda Francesca Liotta and Valeria La Parola

Received: 30 October 2021

Accepted: 11 November 2021

Published: 13 November 2021

Publisher's Note: MDPI stays neutral with regard to jurisdictional claims in published maps and institutional affiliations.

Copyright: (c) 2021 by the authors. Licensee MDPI, Basel, Switzerland. This article is an open access article distributed under the terms and conditions of the Creative Commons Attribution (CC BY) license (https:// creativecommons.org/licenses/by/ $4.0 /)$.

\section{Introduction}

The transition from a fossil-based economy to a bio-based society represents a fundamental goal to diminish environmental issues and reduce the strong dependency on petrochemicals [1]. The replacement of fossil-based fuels and materials with biofuels and bioproducts is of paramount importance for this transition. Catalysis is the core of modern chemical conversions and a key component of sustainable chemistry. The production processes for the vast majority of our fuels and chemicals use catalysts [2].

However, two of the main drawbacks of the catalytic valorization of lignocellulosic biomass are the relatively low stored potential chemical energy as well as the high oxygen content [3]. Hence, there is great interest in valorizing biomass to value-added compounds. Towards this end, new catalytic processes with higher efficiencies, greater tolerance to diverse biomass feedstock, and longer catalyst lifetimes require significant development across disciplines [4,5].

In particular, homogeneous catalysis is a unifying technology, pursuing the yield of valuable feedstock from biomass with more efficient, selective, environmentally benign, and cost-effective catalytic systems [6,7]. A major new development in homogeneous catalysis is the application of organometallic complexes as catalysts [8-11]. Using new catalysts and atom-economical methodologies leads to potential benefit for both the organic synthesis and biomass valorization communities [12].

These new strategies promote the adoption of renewable chemicals produced from biomass as part of the establishment of biorefineries. In addition to converting biomass into alternative fuels and chemicals, this feedstock can be brought into play to render many other processes sustainable. Moreover, life cycle assessment models have shown that bio-based chemicals can have $60-95 \%$ lower carbon footprints compared with petroleum derived chemicals [13].

Biomass transformation involves multiple processing steps in which it gets depolymerized and converted to furfurals. The catalytic upgrading of furfurals is one of the most important steps to produce biofuels and renewable chemicals. Among many biomassderived products, furanics have been extensively studied using biocatalysis [14], homoge- 
neous [8-11] and heterogeneous catalysis [15], and electrocatalysis [16] in different reaction media. Furanics can be produced from non-edible biomass and provide opportunities for sustainable new products often with unique properties that can be used, for example, in the polymer, solvent, and surfactant industries [17,18].

In this context, cellulose- and hemicellulose-derived furans, namely, furfural (FAL), methyl furfural (MF), 5-hydroxymethylfurfural (HMF), 2,5-furandicarboxylic acid (FDCA), 2,5-diformylfuran (DFF), 2,5-bis(hydroxymethyl)furan (DHMF), furfuryl alcohol (FA), 5-methyl furfuryl alcohol (MFA), and 2,5-dimethylfuran (DMF) already represent an important class of bio-based substrates for modern biorefineries (Figure 1) [19,20]. In fact, in the biorefinery strategy, HMF stands out as a sustainable alternative towards fuels, chemicals, and materials, and could eventually replace petroleum-derived products [21].

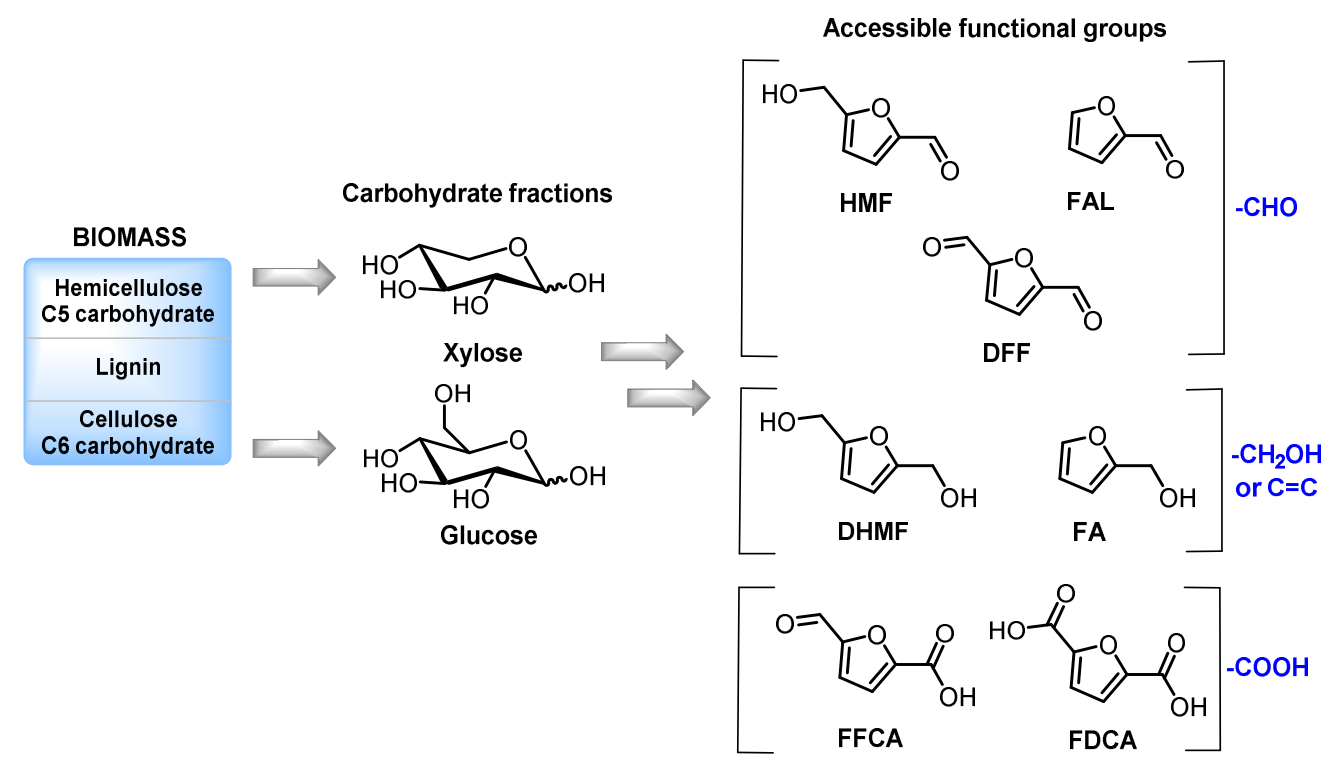

Figure 1. Examples of furanic substrates and target functionalities.

For instance, hydrodeoxygenation (HDO) and deoxygenation (DO) of furans (including HMF) produce value-added chemicals and liquid fuels [22-24]. In the HDO process, hydrocarbon components are generated from biomass derivatives with lower oxygen content via a catalytic reaction in the presence of $\mathrm{H}_{2}$ [25]. In the DO procedure, the modification of the hydrocarbon skeleton is carried out by the removal of oxygen through hydrogenation, decarboxylation, decarbonylation, and dehydration without hydrogen gas [26,27].

Furthermore, these furan derivatives are used as valuable $\mathrm{C} 5 / \mathrm{C} 6$ resources for the synthesis of chemicals and biofuel components, such as levulinic acid (LA), succinic acid, 1,6-hexanediol, cyclopentatone, adipic acid, furoic acid, etc. [28]. Moreover, C5/C9 alkanes can also be produced by the hydrolytic ring opening and complete hydrogenation of furans and their aldol products [29].

This review highlights recent advances in which homogeneous catalyzed reactions transform biomass-derived furanics into renewable and more valuable platform chemicals. In particular, furanic-based derivatives produced by homogeneously catalyzed processes, such as hydrogenation, oxidation, amination, condensation, halogenation, esterification, decarbonylation, and ring opening, are described. We will illustrate the recent development of well-defined and selective catalysts whose performance and stability are positioning homogeneous catalysis as key technologies for biomass transformation.

\section{Homogeneous Catalysts as a Toolbox for Biorefining}

Nature has been refining catalysts for life-sustaining reactions for billions of years [30]. The design of robust non-biological catalysts enable fast and selective chemical transformations under conditions that are currently not possible. 
Hence, there is an enormous opportunity for developing homogeneously catalyzed processes, to re- and defunctionalize biogenic substrates and deliver the production of high-value chemicals [31]. The use of catalysts has potential advantages, including using oxygenated functionalities present in biomass, avoiding the use of harmful reagents, and, in some cases, offering a high yield route [32]. This technology offers the opportunity to fulfill green chemistry requirements, particularly reduced energy consumption, the manufacture of bulk chemicals (which ensures high atom economies [3] or E factors), and the production of biodegradable substances [33].

Homogeneous catalysis often works at much lower temperatures than heterogeneous catalysis, which is highly advantageous when it comes to avoiding side reactions, such as condensation. In fact, noble-metal complexes are well established as catalysts for the catalytic conversions of key intermediates derived from biomass.

The significance of homogeneous catalysis is growing rapidly particularly in the area of the pharmaceutical and polymer industry. For instance, William. S. Knowles, Ryoji Noyori and K. Barry Sharpless received the Nobel Prize in 2001 for their achievements in the field of asymmetric homogeneous catalysis. Their discoveries contributed to the development of industrial syntheses of pharmaceutical products and other biologically active substances [34].

For example, the successful industrial synthesis of the amino acid L-DOPA was developed by Knowles at Monsanto. This chiral drug for treating Parkinson's disease was synthesized using the $[\mathrm{Rh}((R, R)-\mathrm{DiPAMP}) \mathrm{COD}] \mathrm{BF}_{4}$ complex in quantitative yield with $95 \%$ of enantiomeric excess (ee) [35-37].

The Takasago process catalyzed the asymmetric isomerization of an allylic amine to an enamine with the (S)-BINAP-Rh complex and furnished the industrial syntheses of the chiral aroma substance menthol $[38,39]$ with approximately 1000 tons of the annual world production [40]. Another well-known example is the enantioselective hydrogenation or transfer hydrogenation of aldehydes and ketones. This method allows the industrial-scale production of optically active compounds, including medicines, agrochemicals, and perfumes.

Among them, Noyori type catalysts have shown high productivity (turnover number, TON up to $10^{6}$ ), high turnover frequency (TOF) under mild conditions, and excellent enantioselectivity ( $95 \%$ ee) similar to enzymes [41]. This process constitutes one of the most efficient artificial catalytic reactions developed to date. A broader applications of Noyori's catalyst includes $\mathrm{Rh}(\mathrm{I})$ and $\mathrm{Ru}(\mathrm{II})$ species, where BINAP-Ru is used as a catalyst in the industrial production of the anti-inflammatory naproxen (Figure 2) [42,43].

Considering these examples, the conversion of bio-based feedstocks represents a huge challenge for catalysis. The design of a catalyst for biomass transformations requires the development of water tolerant catalysts that are highly resistant to acidic and chelating media and to the impurities present in the fermentation broth [44]. Furthermore, catalysts with strong hydrogenation and finite deoxygenation abilities are necessary for the upgrading of biomass [45].

The catalytic deoxygenation of biomass is very important to produce highly functional intermediates, such as furanics with aldehyde and alcohol moieties [46]. Those chemicals can be produced via different processes. For example, the typical reactions that the furanic aldehyde functionality can undergo are reduction to alcohols by $\mathrm{H}_{2}$ or by hydrogen transfer (Meerwein-Ponndorf-Verley reduction) [47], decarbonylation [48], reductive amination to amines [49], oxidation to carboxylic acid [50], acetalization [51], aldol and Knoevenagel condensations [52], acylation, and Grignard reactions [53]. The second reactive functionality is the hydroxyl group that can undergo hydrogenolysis of the $\mathrm{C}-\mathrm{O}$ bond, oxidation to an aldehyde or acid, etherification, acetalization, esterification, and halogenation reactions [54]. 


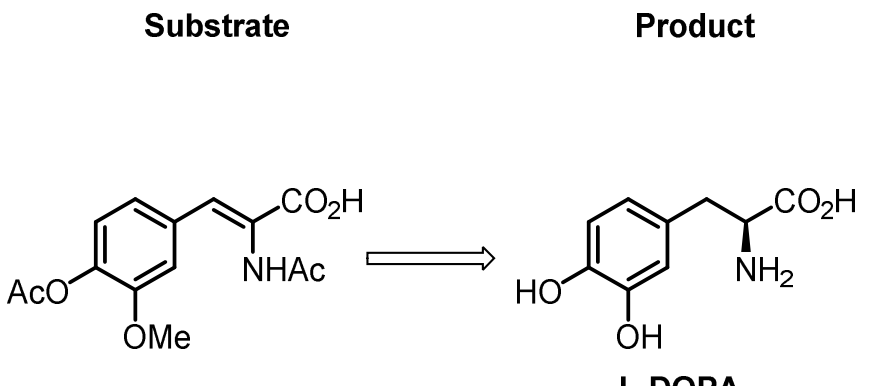

L-DOPA<smiles>C=CC(=C)CCC=C(C)C</smiles><smiles>C=C</smiles><smiles>C=C=C</smiles><smiles>OCC(O)C(O)[C@@H](O)O[C@@H](O)[C@@H](O)CO</smiles>

Sugars<smiles>CC(C(=O)O)[C@H](C)c1ccc2ccccc2c1</smiles><smiles>O=Cc1ccc(CO)o1</smiles>

\section{Furanics}

- Functionalization

- Reduction

- Oxidation

- Other transformations
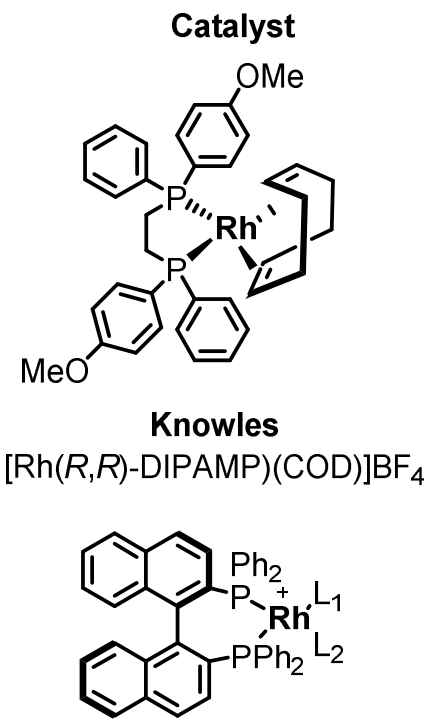

Takasago $\mathrm{Rh}(\mathrm{S})$-BINAP)L

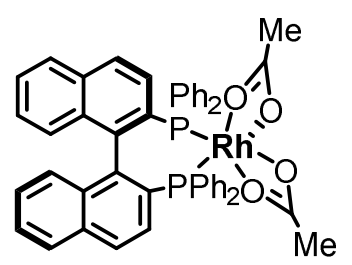

Noyori

S-BINAP Ru(OAc) ${ }_{2}$

$\mathrm{Ru}, \mathrm{Rh}, \mathrm{Ir}, \mathrm{Mn}, \mathrm{Fe}$

Figure 2. Examples of homogeneous catalyzed processes in industry.

Finally, the furan ring can be transformed by hydrogenation, ring-opening, alkylation, oxidation, halogenation, and nitration reactions [55-57]. In general, these reactions lead to liquid alkanes, solvents, fuel additives, plasticizers, and resin precursors. These transformations involve at least one step of an addition of hydrogen to reduce an unsaturated double bond or simply promote the cleavage of a single bond.

\section{Homogeneous Catalysts for the Production of FAL and HMF}

Furanic energy platform chemicals, such as FAL and HMF, can be produced by hydrothermal conversion of biomass [58]. Both chemicals are extremely relevant for biofuel and bio-based chemical industries.

The development of process technologies and implementation of industrial-scale HMF production has been reported [59-61]. Compared to FAL, HMF is an important building block widely recognized for the production of liquid fuels, resins, solvents, pharmaceu- 
ticals, and fine chemicals $[4,62,63]$. The current commercial production of HMF mostly relies on the syrups extracted from energy crops [64,65]. However, the use of different biomass resources or food wastes as an alternative feedstock could enable more sustainable manufacturing practices.

For instance, AVA Biochem produces HMF from lignocellulose at various levels of purity (up to $\geq 99.9 \%$ ) [66]. In this case, the hydrothermal carbonization of lignocellulose towards hydrochar is combined with the production of HMF. Thus, the lignocellulosic biomass is decomposed under high temperature $\left(200-300{ }^{\circ} \mathrm{C}\right)$ and pressure to glucose and fructose in the presence of water. Further dehydration of fructose leads to a HMFcontaining water mixture that is subjected to extraction and separation from the reaction mixture $[58,67]$.

Likewise, FAL is an important renewable, non-petroleum based chemical feedstock. The industrial production of FAL is based on biomass hydrolysis and subsequent dehydration of the obtained pentoses using a homogeneous Brønsted acid catalyst in aqueous media [68]. The furanic platform chemicals are one of the most notable examples of the biorefinery process [69]. The worldwide production of FAL was estimated at nearly $500 \mathrm{kT}$ per year [70]. However, the present yield of FAL in industrial processes is relatively low (approximately 50\%) [58]. The condensation and degradation products as well as the formation of humins decrease the efficiency of the process. Many attempts to increase the yield have suggested the addition of ionic liquids, biphasic systems, and heterogeneous and homogeneous catalysts.

Diverse catalysts and methodologies are employed for the synthesis of HMF and FAL (Figure 3). In general, the dehydration of fructose produces HMF under acidic conditions at elevated temperatures in water. It is well known that fructose is the most convenient starting material for the preparation of HMF, while glucose is less reactive and undergoes isomerization to yield fructose before the dehydration [71]. Likewise, the subsequent rehydration of HMF may occur, and its rearrangement leads to the formation of LA and formic acid [72].

This pathway can influence the overall efficiency of the process leading to the formation of humin-like furanic polymers due to the low stability of HMF [73,74]. To prevent this, Ishida reported the reaction in DMSO, affording high yields of HMF in the presence of Lewis acids, such as $\mathrm{LaCl}_{3}$ at $140{ }^{\circ} \mathrm{C}[72,75]$. Another strategy for the direct production of HMF from various carbohydrates is the use of ionic liquids (ILs) in the presence of a series of relatively eco-friendly metal chlorides.

For instance, Zhao described a pioneering work of the use of [EMIM] $\mathrm{Cl}$ with various metal chlorides, such as $\mathrm{CrCl}_{2}, \mathrm{FeCl}_{2}, \mathrm{FeCl}_{3}, \mathrm{VCl}_{3}, \mathrm{MoCl}_{3}, \mathrm{PdCl}_{2}, \mathrm{PtCl}_{4}, \mathrm{RuCl}_{3}$, and $\mathrm{RhCl}_{3}$ achieving high catalytic activities for the dehydration of fructose to $\mathrm{HMF}$ with yields ranging from $60-83 \%$ at $80{ }^{\circ} \mathrm{C}$ [76]. Interestingly, $\mathrm{CrCl}_{2}$ showed better activity for the conversion of glucose to $\mathrm{HMF}$ with a $70 \%$ yield in $3 \mathrm{~h}$ at $100{ }^{\circ} \mathrm{C}$. In fact, $\mathrm{CrCl}_{2}$ reacts with the IL to form active species [EMIM] $\mathrm{CrCl}_{2}$, which facilitates sugar isomerization and dehydration [77].

Other metal chlorides, including $\mathrm{SnCl}_{4}$ [78], $\mathrm{CuCl}_{4}$ [79], $\mathrm{RuCl}_{3}$ [80], $\mathrm{IrCl}_{3}$ [81], $\mathrm{ZrCl}_{4}$ [82], $\mathrm{ZrOCl}_{2}$ [83], $\mathrm{HfCl}_{4}$ [84], $\mathrm{NbCl}_{5}$ [85], and $\mathrm{YCl}_{3}$ [86], have been reported as catalysts for the transformation of carbohydrates into HMF in different solvents. This methodology represents an important advance in the use of lignocellulose for the production of primary furanics via a green process without volatile organic solvents [74,87].

The transition metal chlorides with Lewis acidity promote the aldose-ketose isomerization during the sugar conversion and yield furan platform chemicals (HMF and FAL) with relatively low catalyst loading [53]. The use of ionic liquids as a solvent/additive has been proposed as alternative to promote the hydrothermal conversion of biomass in an indirect recycling of the reaction phase. 


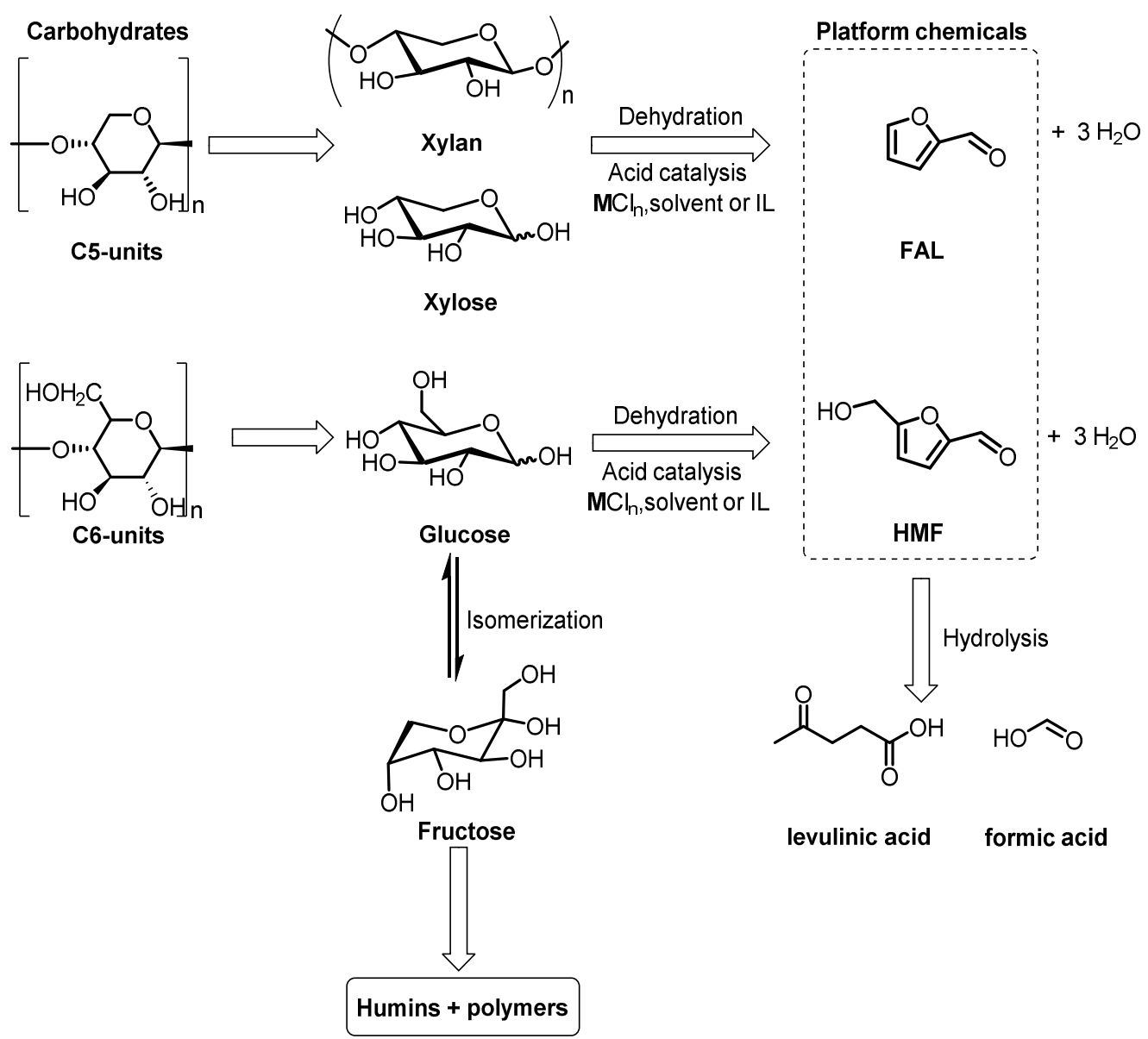

Figure 3. Upgrading of lignocellulosic polysaccharides to the primary furanics FAL and HMF.

Wrigsted explored the use of $\mathrm{CrCl}_{3}$ in the presence of mineral acids and alkali metals salts for the dehydration of glucose and fructose in a water-THF mixture [88]. The addition of acid prevents the formation of a chromium-glucose chelate complex hampering the isomerization of glucose and leading to similar yields of HMF and FAL (53\% and 59\%, respectively).

Lin explored the use of a relatively low-toxic, recyclable, and inexpensive catalytic system with chromium(III) chloride $\left(\mathrm{CrCl}_{3} \cdot 6 \mathrm{H}_{2} \mathrm{O}\right)$ and tetraethylammonium chloride (TEAC) ionic liquid. The efficient conversion of glucose into HMF was achieved in $71 \%$ at $130{ }^{\circ} \mathrm{C}$ in $10 \mathrm{~min}$ [73].

Yadav and coworkers reported the transformation of glucose into HMF promoted by cobalt-based metallophthalocyanines [89]. The results demonstrated high catalytic activity of the cobalt phthalocyanine (Co-PC) with an electron-withdrawing nitro group. Subsequent studies with this catalytic system suggested that stronger Lewis acidity in combination with ionic liquids ([EMIM]Cl or $[\mathrm{BMIM}] \mathrm{Cl})$ could improve the conversion of glucose into $\mathrm{HMF}$ in high yields $(>88 \%)$ at $100{ }^{\circ} \mathrm{C}$ after $3 \mathrm{~h}$.

Among these examples, metal triflates constitute a viable alternative for the production of HMF with much lower corrosion and environmental pollution. In particular, Wang and coworkers investigated the catalytic activity of various triflate salts from which $\mathrm{Sc}(\mathrm{OTf})_{3}$ and $\mathrm{Yb}(\mathrm{OTf})_{3}$ showed an $80 \%$ yield in DMSO at $120{ }^{\circ} \mathrm{C}$ and $2 \mathrm{~h}$ [90]. Likewise, Li investigated the production of $\mathrm{HMF}$ from glucose when using $\mathrm{Hf}(\mathrm{OTf})_{4}$ in sec-butyl phenol at $165^{\circ} \mathrm{C}$ and $25 \mathrm{~min}$. The higher valence state of the metal cations involves stronger Lewis acidities facilitating the isomerization of glucose and the dehydration of fructose while improving the yield of HMF. 
Other substrates, like xylose, can be subjected to similar reactions with $\mathrm{HCl} / \mathrm{CrCl}_{3}$ catalytic mixture in aqueous media producing FAL in 39\% yield [91]. Marcotullio [92,93] and Liu [94] found that the use of $\mathrm{FeCl}_{3}$ increased the rate of conversion of xylose or xylotriose in water or water-CPME (cyclopentyl methyl ester) mixtures at $180{ }^{\circ} \mathrm{C}$. The conversion rate was improved under these reaction conditions, reaching a $65-74 \%$ yield for of xylose and $78 \%$ for xylotriose. Overall, furans produced from carbohydrates have high potential for the synthesis of useful monomers based on renewable sources. In the next sections, we will discuss the most relevant transformation of bio-based furanics, such as FAL and HMF compounds, by homogeneous catalysts.

\section{Catalytic Reduction of Furanics}

The currently forecasted transition to a hydrogen economy allows the use of renewable hydrogen as clean energy source for many applications [95]. For example, green and sustainable organo synthesis can use renewable hydrogen to achieve the chemical reduction of carbohydrate-based feedstocks and convert the highly unsaturated biomass to valueadded chemicals. Thus, the efficient hydrogenation of carbonylic functionalities in biomass derived substrates, such as HMF, FAL, and MF, represent a good strategy in organic synthesis for the sustainable production of fuels or building block chemicals [96].

In fact, the selective hydrogenation of HMF into DHMF is very similar to the reduction of $\alpha, \beta$-unsaturated aldehydes or ketones to the corresponding unsaturated alcohols [97]. This reductive process has been achieved by different hydrogenation methodologies, including electrocatalytic hydrogenation [98] or in the presence of heterogeneous catalysts at high temperatures and pressures [99].

However, most of the catalysts compromise the activity to attain high selectivity by modifying the active metal with second components or introducing additives or oxide supports. In particular, Tomishige reported a heterogeneous multicomponent-based Ir-Re catalyst supported on $\mathrm{SiO}_{2}$ for the selective hydrogenation of HMF to DHMF in high yield (99\%) under 8 bar $\mathrm{H}_{2}$ at $30{ }^{\circ} \mathrm{C}[96,100]$.

Moreover, DHMF is an important starting molecule for the polymerization or etherification processes (biodiesel, polyester, and polyurethane foams) [98]. Other bulk chemicals are derived from FAL, such as FA, methyl-tetrahydrofuran (MTHF), THF, and maleic acid (MA) [26].

Conventionally, furfuryl alcohol is produced over copper-chromite catalysts, which are highly toxic and cause serious environmental issues [101]. Therefore, the exploration of non-chromium catalysts for the green catalysis of FAL hydrogenation to FA is ongoing. For example, heteropolyacid catalysts have shown potential for this hydrogenation process, which is of great interest as a building block for resins [102]. An alternative to these solid Lewis acid catalysts is the addition of mineral acids $\left(\mathrm{H}_{2} \mathrm{SO}_{4}, \mathrm{HCl}\right.$, and $\left.\mathrm{H}_{3} \mathrm{PO}_{4}\right)$ and salts with transition metals $\left(\mathrm{CrCl}_{3}\right.$ and $\left.\mathrm{SnCl}_{4}\right)$ in aqueous media [103].

Even though these catalytic advances in the production of biomass-derived furanic alcohols provide green alternatives to stoichiometric reducing agents, homogeneous catalysis that, in principle, might improve selectivity under mild reaction conditions, have been scarcely investigated. A gradual evolution of the catalytic hydrogenation of HMF to DHMF by homogeneous catalysts has been described using high-pressure $\mathrm{H}_{2}$ gas or other hydrogen sources and an inorganic/organic base (Figure 4).

For example, Elsevier studied the catalytic hydrogenation of HMF with a half-sandwich $\mathrm{Ru}-\mathrm{NHC}$ complex $(0.5 \mathrm{~mol} \%)$ in the presence of $\mathrm{KOtBu}$ and THF under 50 bar $\mathrm{H}_{2}$ at $70{ }^{\circ} \mathrm{C}$ [104]. This catalytic system showed a 99\% conversion after $2 \mathrm{~h}$ and was successfully extended to other key biomass-derived substrates, such as cinnamaldehyde or dimethyl oxalate. Furthermore, Hashmi investigated the same reductive process using $\mathrm{Ru}$ (methylallyl) ${ }_{2} \mathrm{COD}\left(4.5 \mathrm{~mol} \%\right.$ ) combined with an NHC-based ligand at $10 \mathrm{bar}_{2}$ and $120{ }^{\circ} \mathrm{C}$ [105]. The reaction afforded $92 \%$ yield of DHMF and $12 \%$ of the side product THFDM after $16 \mathrm{~h}$. 
Mazzoni reported the use of the dimeric Shvo's catalyst $(0.1 \mathrm{~mol} \%)$ to produce DHMF in toluene $/ \mathrm{H}_{2} \mathrm{O}$ under 10 bar $\mathrm{H}_{2}$ at $90{ }^{\circ} \mathrm{C}$ in $99 \%$ yield [106]. Recently, Nielsen reported the highly effective and selective hydrogenation of the bio-based furanic aldehydes, such as HMF and MF under mild reaction conditions to the corresponding alcohols catalyzed by Ru-PNP and Ir-PNP complexes under 30 bar $\mathrm{H}_{2}$ at $25^{\circ} \mathrm{C}$ and $60{ }^{\circ} \mathrm{C}$, respectively [107]. This methodology allowed a high conversion rate up to TOF $>1900 \mathrm{~min}^{-1}$ and the quantitative isolated yield of DHMF and MFA.

This work showed solvent-free catalytic reactions in large scale, which is important to reduce costs and the environmental impact as well as to improve the efficiency [108]. In another attempt, Beller demonstrated the use of a base-metal PNP-Mn complex (1 mol\%) for the production of DHMF in toluene under 30 bar $\mathrm{H}_{2}$ at $100{ }^{\circ} \mathrm{C}$, affording $90 \%$ conversion after $24 \mathrm{~h}$ [109]. Unfortunately, efforts to isolate the product remained cumbersome during the purification yielding $64 \%$ of the product due to decomposition.

There is also an important need for the development of environmentally benign technologies to improve the catalytic efficiency of FA production. Currently, FA is the most important monomer in furfural-based polymers [110]. Some technologies propose the production of bifunctionalized monomers from FA and its derivatives as precursors for po- lymer synthesis. In fact, biorenewable C5 alcohols are considered important commodity chemicals for the production of polyesters, polyurethanes, polyethers, and fuel additives [68].

In this sense, there are several promising alternatives for the production of FA. For example, Li [111], Bhanage [112], and Rothenberg [113,114] used a Ru-catalyst for the reduction of FAL to FA at a low temperature in the presence of different solvents. Mika also reported $\mathrm{Ru}(\mathrm{acac})_{3}$ pre-catalyst in the presence of a bidentade ligand DPPB (1,4-bis(diphenylphosphino)butane) at $160{ }^{\circ} \mathrm{C}$ in EtOAc for $0.6 \mathrm{~h}$ with a maximum TOF $=6273 \mathrm{~h}^{-1}$ and $99 \%$ conversion [115]. Ladipo explored the activity of cis-[Ru(6,6'$\left.\mathrm{Cl}_{2}(\mathrm{bpy})_{2}\left(\mathrm{OH}_{2}\right)_{2}\right]\left(\mathrm{CF}_{3} \mathrm{SO}_{3}\right)_{2}(1 \mathrm{~mol} \%)$ for the production of $\mathrm{FA}$ at $100{ }^{\circ} \mathrm{C}, 51 \mathrm{bar} \mathrm{H}_{2}$ in EtOH [116]. The results displayed good selectivity (99\%) and conversion (99\%) after $2 \mathrm{~h}$.

Deng and Fu reported high turnover numbers, up to $13,877 \mathrm{~h}^{-1}$ and $50 \%$ yield for the transformation of FAL to FA using iridium half-sandwich catalyst $(0.0083 \mathrm{~mol} \%)$ in the presence of a phosphate buffer solution at $120^{\circ} \mathrm{C}, 10$ bar $\mathrm{H}_{2}$ and $4 \mathrm{~h}$ [117]. The side products LA (41\%) and gamma-valerolactone (GVL, 9\%) were also observed. Choudhury accomplished the catalytic reduction of FAL using a neutral iridium half-sandwich system at $30{ }^{\circ} \mathrm{C}, 1$ bar $\mathrm{H}_{2}$ in EtOH/ $\mathrm{H}_{2} \mathrm{O}$ mixture, producing a $94 \%$ yield after $2 \mathrm{~h}$ [118].

Additionally, an efficient catalytic hydrogenation of FAL using Triphos- $\mathrm{Ru}(\mathrm{CO}) \mathrm{H}_{2}$ has been reported by Grainger an coworkers. A catalyst loading of $0.05 \mathrm{~mol} \%$ gave full conversion after $16 \mathrm{~h}$ at $120{ }^{\circ} \mathrm{C}$ and 30 bar $\mathrm{H}_{2}$ [119]. The combination of relatively low catalyst loading of Ru-PNP (0.05-0.1 mol\%) promoted the effective catalytic conversion of FAL to FA in $99 \%$ after 30 min employing mild conditions and green solvents [107].

Among these examples, Makhubela reported the selective production of bio-based alcohols, including FA using a $\mathrm{Pt}(\mathrm{II})$ complex (0.2 mol\%) containing a Schiff base ligand. The catalyst displayed complete conversion of the substrate at $140{ }^{\circ} \mathrm{C}, 20 \mathrm{bar}_{2}$ with good selectivity towards FA in EtOH and 88\% yield after $10 \mathrm{~h} \mathrm{[120].} \mathrm{The} \mathrm{pre-catalyst}$ showed enhanced activity and selectivity in the presence of $\mathrm{HCOOH}$ affording a highest TOF of $1060 \mathrm{~h}^{-1}$. Recently, Aguirre studied the activity of Ru-NPN pincer complex with $0.033 \mathrm{~mol} \%$, producing FA in high yield (99\%) at $120^{\circ} \mathrm{C}$ under $20 \mathrm{bar}_{2}$ in $\mathrm{PrOH}$ [121].

Within this context, the replacement of precious metal catalysts by earth-abundant metals results in a beneficial practice in terms of green chemistry [122]. For instance, Beller reported the first example of a base-metal catalyzed hydrogenation of furanic aldehydes. The Fe(II) tetraphos system $\left[\mathrm{FeFP}\left(\mathrm{PhPPh}_{2}\right)_{3}\right]\left[\mathrm{BF}_{4}\right](0.8 \mathrm{~mol} \%)$ exhibited full chemoselectivity for the reduction of FAL to FA in $i \mathrm{PrOH} / \mathrm{TFA}$ (trifluoroacetic acid) mixture at $120^{\circ} \mathrm{C}$, 20 bar $\mathrm{H}_{2}$ and $2 \mathrm{~h}$.

The desired alcohol was obtained with a 99\% yield [123]. Kirchner studied the same reductive process with Fe-PNP $(0.05 \mathrm{~mol} \%)$ and DBU $(1 \mathrm{~mol} \%)$ at $40{ }^{\circ} \mathrm{C}, 30 \mathrm{bar} \mathrm{H}_{2}$, and $16 \mathrm{~h}$. 
The combination of this catalyst with a supported ionic liquid phase (SILP) promoted the hydrogenation of aldehydes. Kirchner, Hoffmann, and Bica reported the catalytic activity of this system for the reduction of FAL to FA in a mixture of IL/n-heptane in $87-98 \%$ yield under $10-50$ bar $\mathrm{H}_{2}$ at $25^{\circ} \mathrm{C}$ in $1 \mathrm{~h} \mathrm{[124-126].}$

In the case of manganese catalysts, the hydrogenation of carbonyl compounds proceed at relatively high catalyst loading at elevated temperatures in the presence of strong bases [127]. Filonenko and Pidko reported manganese-based hydrogenation catalysis for the conversion of carbonyl derivatives including biomass aldehydes, such as FAL [128]. The $\mathrm{Mn}(\mathrm{I})$-CNP precatalyst (50 ppm) is activated in the presence of a hydride donor promoter $\mathrm{KHBEt}_{3}(1 \mathrm{~mol} \%)$ and 25 bar $\mathrm{H}_{2}, 24 \mathrm{~h}$ at $80{ }^{\circ} \mathrm{C}$ in $i \mathrm{PrOH}$. The desired alcohol (FA) was isolated in $54 \%$ yield (Figure 5). Kirchner improved the yield up to $77 \%$ by using a monohydride Mn-PNP complex $(0.1 \mathrm{~mol} \%)$ and $\mathrm{H}_{2}$ pressure of 50 bar at $25{ }^{\circ} \mathrm{C}$ and $18 \mathrm{~h} \mathrm{[129].}$
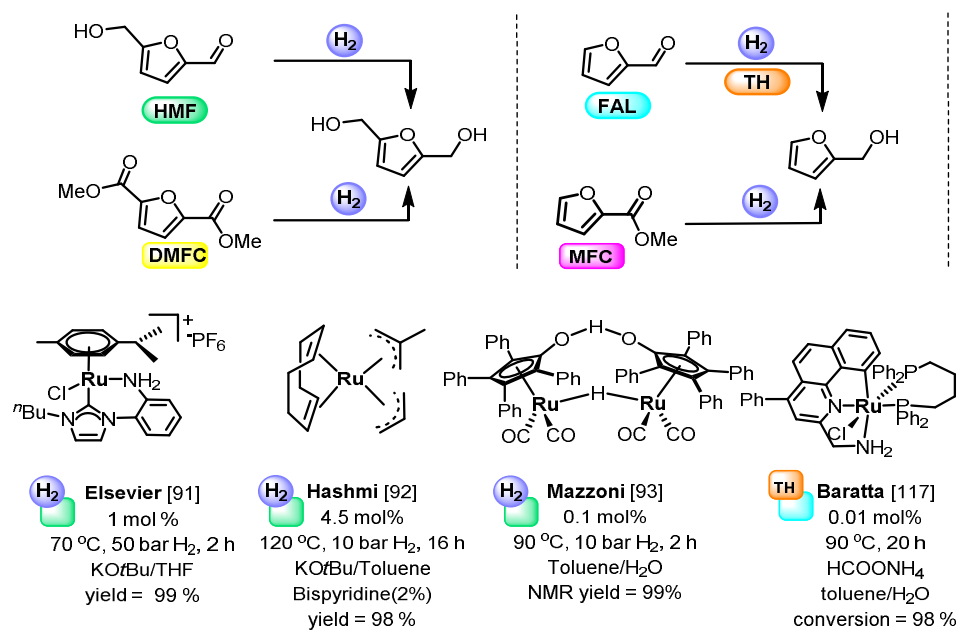
TH Baratta [117]
Baratta [117]
$0.01 \mathrm{~mol} \%$ $90^{\circ} \mathrm{C}, 20 \mathrm{~h}$ $\mathrm{HCOONH}_{4}$ conversion $=98 \%$
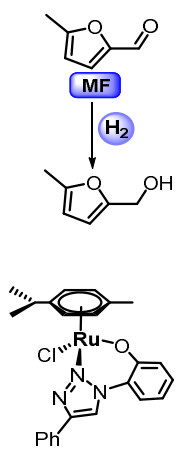
TH Bagh [121] $2 \mathrm{~mol} \%$
$\mathrm{~K}_{2} \mathrm{CO}_{3} / \mathrm{EtOH}$ $70^{\circ} \mathrm{C}, 24 \mathrm{~h}$ yield $=90 \%$
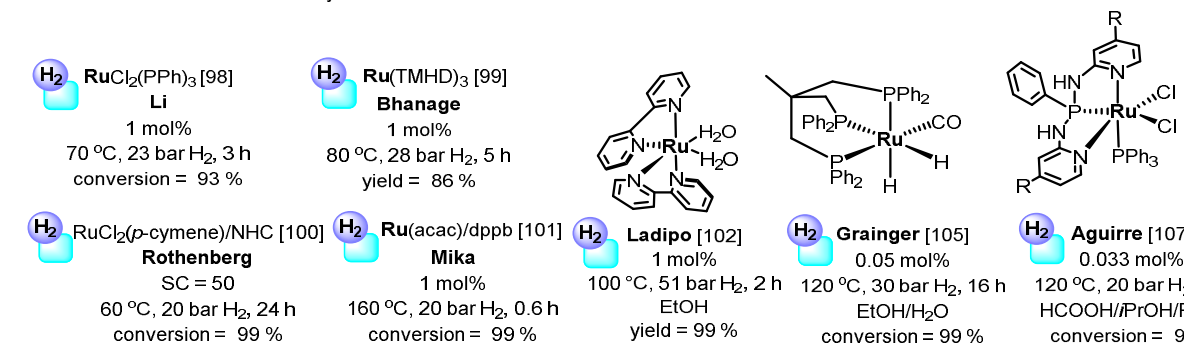

H. Aguirre [107] $120^{\circ} \mathrm{C} .20$ bar $^{2}, 1 \mathrm{~h}$ $\mathrm{HCOOH} / \mathrm{PrOH} / \mathrm{PPh}_{3}$ (conversion $=99 \%$
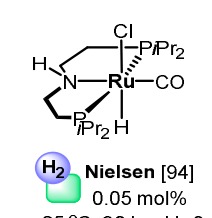
$25^{\circ} \mathrm{C}, 30$ bar $\mathrm{H}_{2}, 0.5 \mathrm{~h}$ $\mathrm{NaOEt} / \mathrm{EtOH}$

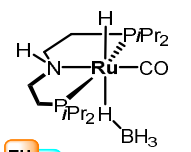

TH de Vries [120] de Vries $[120$
$0.1 \mathrm{~mol} \%$
reflux, $0.5 \mathrm{~h}$ conversion $=99 \%$ $\mathrm{EtOH}$
yield $=79 \%$

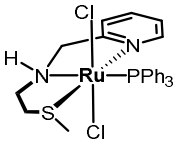

$\mathrm{H}_{2}$ de Vries [125] de Vries [125]
$0.05 \mathrm{~mol} \%$ $80^{\circ} \mathrm{C}, 50$ bar $\mathrm{H}_{2} \quad 60^{\circ} \mathrm{C}, 30$ bar $\mathrm{H}_{2}, 2.5 \mathrm{~h} \quad 130^{\circ} \mathrm{C}, 50$ bar $\mathrm{H}_{2} \quad 30^{\circ} \mathrm{C}, 1 \mathrm{bar} \mathrm{H}_{2}, 2 \mathrm{~h}$ KOtBu/toluene $10 \mathrm{~h}$, yield $=80 \% \quad$ conversion $=99 \% \quad 18 \mathrm{~h}$. yield $=89 \% \quad$ yield $=94 \%$
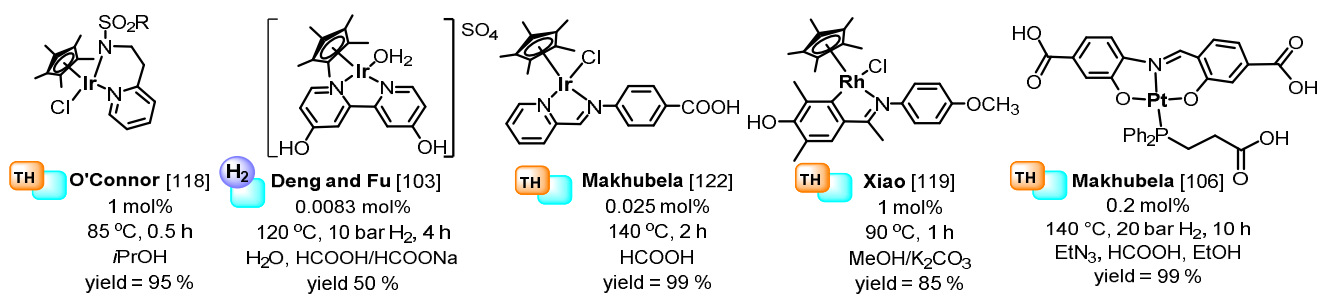

Figure 4. Well-defined precious-metal complexes for the selective hydrogenation/transfer hydrogenation of furanic aldehydes and esters to alcohols. 

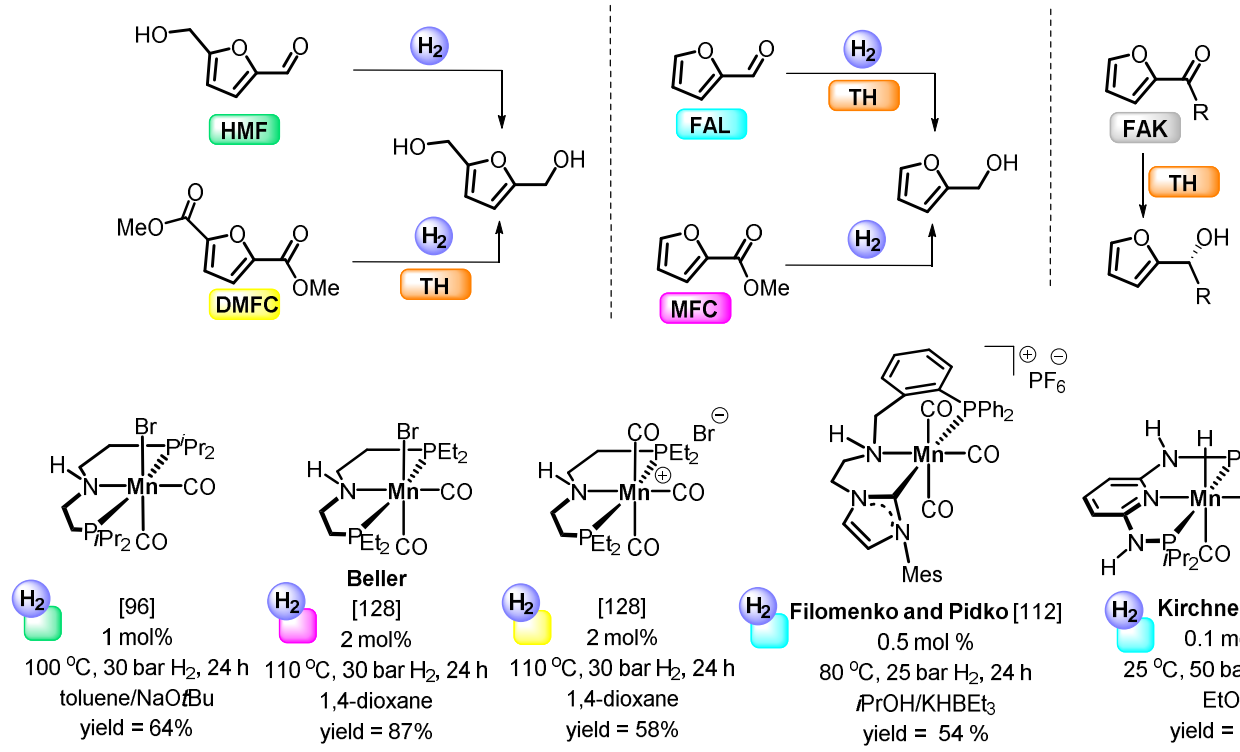

30 bar $_{2}, 24 \mathrm{~h}$

1,4-dioxane

Filomenko and Pidko [112] $0.5 \mathrm{~mol} \%$

$80^{\circ} \mathrm{C}, 25$ bar $\mathrm{H}_{2}, 24 \mathrm{~h}$ $\mathrm{PrOH} / \mathrm{KHBEt}_{3}$ yield $=54 \%$
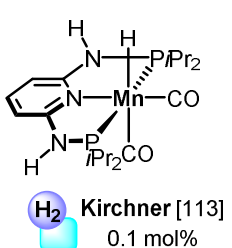

$25^{\circ} \mathrm{C}, 50$ bar $\mathrm{H}_{2}, 18 \mathrm{~h}$

$\mathrm{EtOH}$ yield $=77 \%$
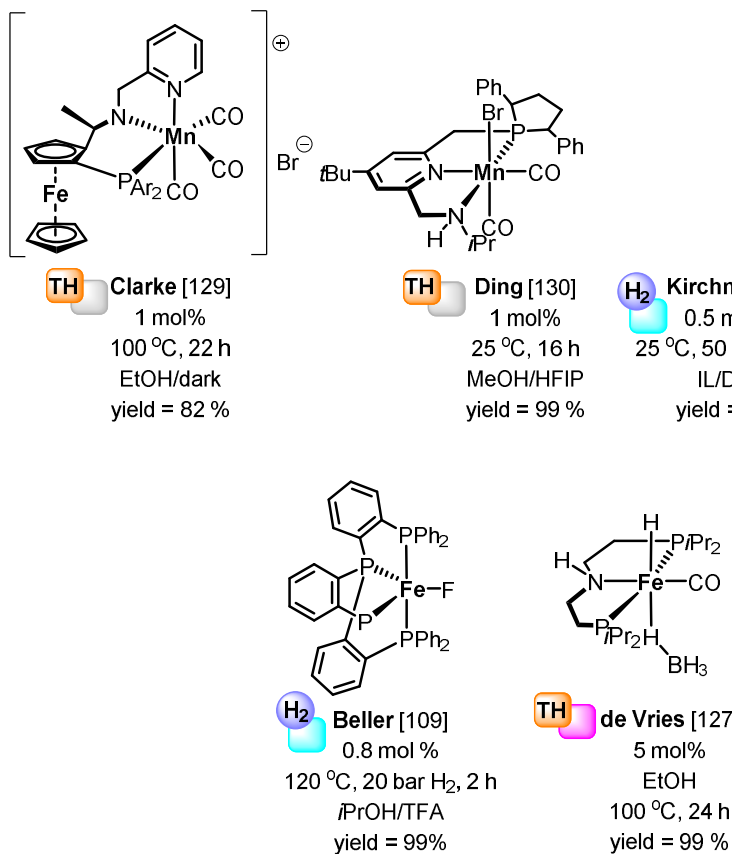
$\mathrm{H}_{2}$ Kirchner, Hoffmann and Bica [110] $0.5 \mathrm{~mol} \%$
$25^{\circ} \mathrm{C}, 50$ bar $\mathrm{H}_{2}, 1 \mathrm{~h} 25^{\circ} \mathrm{C}, 10-50$ bar $\mathrm{H}_{2}, 1 \mathrm{~h}$ IL/DBU yield $=98 \%$

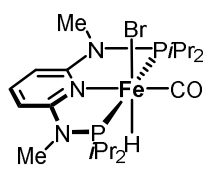

TH Kirchner [123]

$1.0 \mathrm{~mol} \%$

$80^{\circ} \mathrm{C}, 1 \mathrm{~h}$

$\mathrm{NaHCO}_{2} / \mathrm{H}_{2} \mathrm{O}$

yield $=99 \%$

Figure 5. Base-metal complexes for the selective hydrogenation/transfer hydrogenation of furanic ketones as well as aldehydes and esters to alcohols.

To avoid the use of high-pressure reactors and harsh reaction conditions for classical hydrogenation, catalytic transfer hydrogenation is considered an attractive alternative. This process involves the transfer of a proton and a hydride from the donor molecule to the unsaturated substrate. There are examples of sacrificial hydrogen donors, such as formic acid, $\mathrm{iPrOH}, \mathrm{EtOH}$, and $\mathrm{MeOH}$. In fact, the replacement of molecular dihydrogen as a reducing agent by a sacrificial hydrogen donor/solvent, such as EtOH, is an ecofriendly and safe option.

The first example of transfer hydrogenation of carbonyl compounds is the well-known Meerwein-Ponndorf-Verley reduction, which involved the use of aluminum alkoxide as a promoter for the reduction of a ketone in the presence of a secondary alcohol as a sacrificial hydrogen source [130]. Although this process has been widely utilized in both academic and industrial processes, the major drawbacks of this protocol are the requirement of a large amount of aluminum alkoxide reagent, unwanted side reactions, 
and the moisture sensitivity of aluminum alkoxides [131]. The catalytic TH is a relatively new process in biomass value addition with outstanding results for the production of biofuels. Furthermore, this synthetic procedure decreases the risk of overpressure in the system and simplifies the reactor design.

Several iridium and ruthenium-based catalysts have been reported for the selective transfer hydrogenation of aldehydes using water as solvent and formates as hydrogen source. On the other hand, secondary alcohols have a higher tendency to release hydrogen than primary alcohols [132,133]. Often the combination of a hydrogen donor and $\mathrm{H}_{2}$ gas is necessary to avoid the oxidized product of the raw material or aldehydes and ketones from the alcoholic hydrogen donor.

The chemoselective reduction of FAL to the corresponding alcohol was achieved by Baratta and coworkers using benzo[h]quinoline $\mathrm{RuCl}_{2}\left(\mathrm{CNN}^{\mathrm{Ph}}\right)(\mathrm{PP})$ pincer complex $(0.01 \mathrm{~mol} \%)$ and $\mathrm{HCOONH}_{4}$ as a hydrogen donor. The heteroaromatic aldehyde was selectively reduced to FA with a conversion of $98 \%$ at $90^{\circ} \mathrm{C}$ in toluene/water after $20 \mathrm{~h}$ [134].

$\mathrm{O}^{\prime}$ Connor established a proof of concept for TH of HMF under base-free conditions employing $i \mathrm{PrOH}$ as a source of hydrogen. The complete reduction of the aldehyde functionality was carried out with a $\mathrm{Cp}{ }^{*} \operatorname{Ir}$ (pyridinesulfonamide) $\mathrm{Cl}$ complex $(1 \mathrm{~mol} \%)$ at $85{ }^{\circ} \mathrm{C}$ in 30 min. Both HMF and FAL were reduced with $99 \%$ and $95 \%$ yields, respectively. This represents one of the few examples for the selective hydrogenation of furanic aldehydes without base or formation of side products [135]. In contrast, Xiao explored the TH of HMF using a rhodaclycle $\left(1 \mathrm{~mol} \%\right.$ ) with $\mathrm{MeOH}$ and $\mathrm{Cs}_{2} \mathrm{CO}_{3}$ as base. The productivity of this complex along with its high stability provided $82 \%$ yield at $90{ }^{\circ} \mathrm{C}$ in $1 \mathrm{~h} \mathrm{[136]}$.

Similarly, de Vries reported using Ru-MACHO-BH (0.1 mol\%) complex for the TH of FAL using $i \mathrm{PrOH}$ or EtOH as a hydrogen source [137]. The desired product was isolated in $79 \%$ yield after $16 \mathrm{~h}$ under reflux. A contrasting system was developed by Bagh and coworkers for the TH of FAL using a phosphine-free air-stable ruthenium(II)-triazole complex $(2 \mathrm{~mol} \%)$ in the presence of $\mathrm{EtOH}$ and $\mathrm{K}_{2} \mathrm{CO}_{3}$ at $70{ }^{\circ} \mathrm{C}$. The reaction provided a $90 \%$ yield of FA [138].

Makhubela tested the efficiency of pyridyl-imine iridium(III) for the production of FA with $\mathrm{HCOOH}$ as the source of hydrogen using a catalyst loading as low as $0.025 \mathrm{~mol} \%$ and $\mathrm{Et}_{3} \mathrm{~N}$ as a base [139]. The catalyst showed good selectivity with TOF of $1481 \mathrm{~h}^{-1}$ and $74 \%$ conversion at $140{ }^{\circ} \mathrm{C}$.

The expansion of catalytic reduction of aldehydes can also use base-metal catalytic systems. For example, Kirchner used Fe-PNP hydride complex for the TH of FAL employing $\mathrm{NaHCO}_{2} / \mathrm{H}_{2} \mathrm{O}$ at $80{ }^{\circ} \mathrm{C}$ producing a $99 \%$ yield of $\mathrm{FA}$ after $1 \mathrm{~h}$ [140]. Symes reported the combination of the reducing agent $\mathrm{NaCNBH}_{3}$ as hydride source and Nitschke's $\mathrm{Fe}_{4} \mathrm{~L}_{6}$ cage as an enzyme-like catalyst. The encapsulation of furfural inside a supramolecular cage prevents the oligomerization of reactive intermediates and selective production of FA and 2-methylfuran [141].

Other outcomes for the hydrogenation of aldehydes enabled the reduction of carbonylic moieties, such as esters. In particular, de Vries demonstrated the effective ester hydrogenation of methyl furan 1-carboxylate (MFC) to FA with $0.05 \mathrm{~mol} \%$ of Ru-NNS complex. Presumably, the use of toluene maximizes the conversion and yield of FAL to $80 \%$ at $80{ }^{\circ} \mathrm{C}, 50$ bar $\mathrm{H}_{2}$, and $10 \mathrm{~h}$ [142].

Similarly, Beller described the use of a PNP-Ir complex for the reduction of MFC to the corresponding alcohol. The reaction was carried out with $2 \mathrm{~mol} \%$ catalyst loading in the presence of $\mathrm{NaOMe}$ under 50 bar $\mathrm{H}_{2}$ and $130{ }^{\circ} \mathrm{C}$. The product was isolated in $89 \%$ yield after $18 \mathrm{~h}$ [143].

Parallel to these works, de Vries explored the hydrogenation of esters catalyzed by PNP-pincer base metal complexes. In this regard, Fe-MACHO-BH (5 mol\%) promoted the reduction of MFC to FA (99\% yield) in $\mathrm{EtOH}$ at $100{ }^{\circ} \mathrm{C}$ and $24 \mathrm{~h}$ [144]. Interestingly, high yields of FA ( $87 \%$ ) were also observed with the PNP-Mn catalyst ( $2 \mathrm{~mol} \%)$ in 1,4-dioxane at $110{ }^{\circ} \mathrm{C}$ and 30 bar $\mathrm{H}_{2}$ [128]. In addition, the hydrogenation of dimethyl furan-2,5- 
dicarboxylate (DMFC) towards BHMF was afforded with a $58 \%$ yield by using the cationic Mn-PNP tricarbonyl complex (2 mol\%) under similar reaction conditions [109,145].

Clarke used a Mn-PNN complex for the TH of MFC at $100{ }^{\circ} \mathrm{C}$ in the presence of $\mathrm{KO} t \mathrm{Bu}$ and $\mathrm{EtOH}$. A catalyst loading of $1 \mathrm{~mol} \%$ achieved an $82 \%$ yield after $22 \mathrm{~h}$ [146]. Likewise, the enantioselective ketone hydrogenation has been demonstrated in recent years. For instance, Ding reported a lutidine-based chiral Mn-PNN complex for the asymmetric hydrogenation of 2-acetylfuran employing $1 \mathrm{~mol} \%$ of the catalyst under milder reaction condition [147]. The heteroaromatic ketone was reduced to the corresponding chiral alcohol in $99 \%$ yield and $85 \%$ ee.

Among these examples, other processes and catalytic systems have been developed for the transformation of furanic aldehydes into hydrogenation/ring opening products such as ketoacids and diketones. For instance, 1-hydroxyhexane-2,5-dione (HHD) is one of the ketone derivatives obtained from HMF (Figure 6). It is considered an important intermediate generated in-situ for the formation of cyclopentanone-based chemicals through aldol-condensation [148].

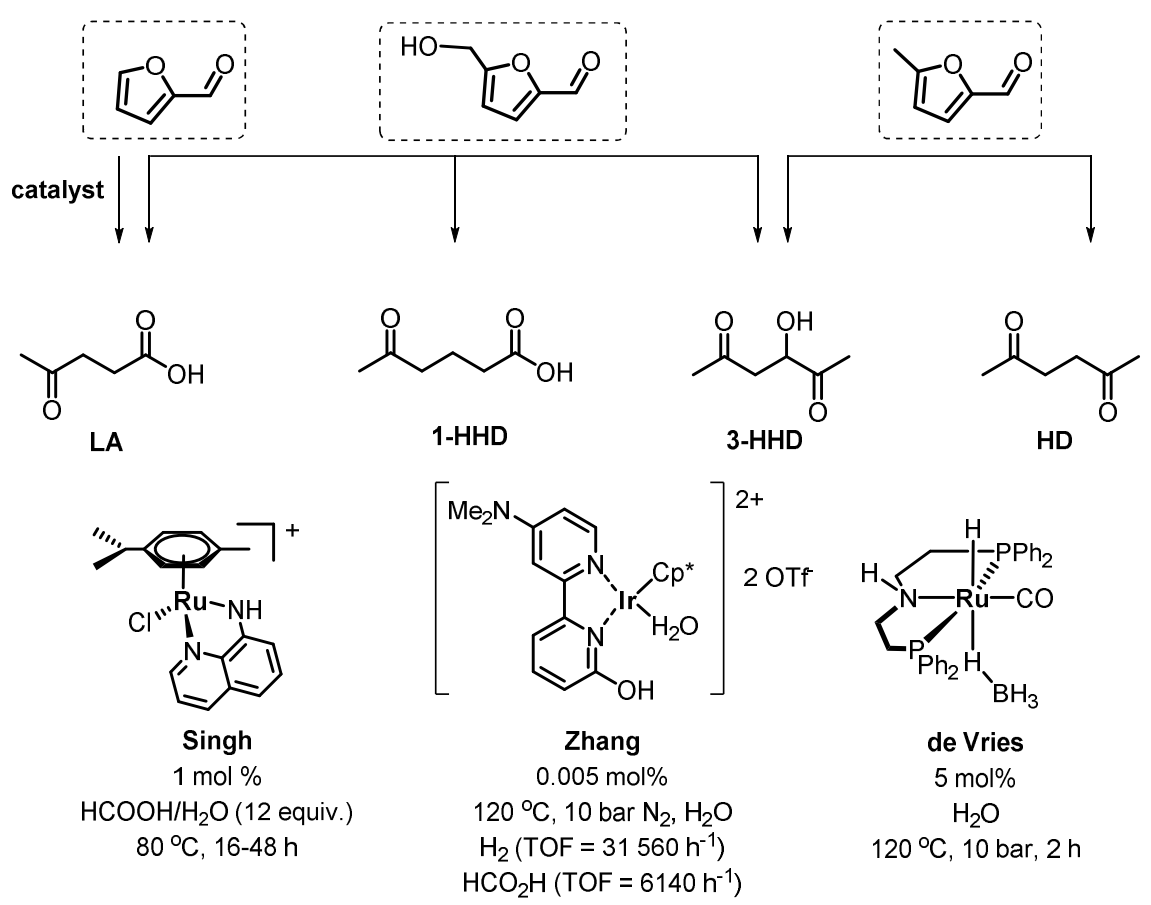

Figure 6. Ring opening reduction of furanic aldehydes with transition metal catalysts.

The transformation of furans (HMF, FAL, and MF) to ketoacids and diketones was studied by Singh and coworkers employing the water soluble 8-aminoquinoline areneruthenium (II) complex [149]. This one pot catalytic transformation allows the production of levulinic acid, 1-hydroxy-hexane-2,5-done (1-HHD), 3-hydroxyhexane-2,5-dione (3-HHD) and hexane-2,5-dione (HD) in the presence of $1 \mathrm{~mol} \%$ catalyst and an excess of $\mathrm{HCOOH}$ at $80-100{ }^{\circ} \mathrm{C}$. This H-donor source is non-toxic organic acid and in combination with water as solvent, facilitate the hydrolytic ring opening of furans.

Zhang investigated the catalytic hydrogenation of HMF using a family of bipyridine $\mathrm{Cp}^{*} \mathrm{Ir}(\mathrm{III})$ complexes [150]. Thus, the hydrogenation and hydrolytic ring opening of HMF with the half-sandwich complex $(0.26 \mathrm{~mol} \%)$ in $\mathrm{H}_{2} \mathrm{O}$ under 20 bar $\mathrm{H}_{2}$ at $110^{\circ} \mathrm{C}$ for $1 \mathrm{~h}$, produced $86 \%$ of HHD. Further studies with analogous $C \mathrm{p}^{*} \operatorname{Ir}(\mathrm{III})$ precatalyst containing a functionalized bipyridine and lower catalyst loading $(0.00083 \mathrm{~mol} \%)$ afforded a TOF $=31,560 \mathrm{~h}^{-1}$ and $67 \%$ yield at $120^{\circ} \mathrm{C}, 35 \mathrm{bar} \mathrm{H}_{2}$ for $6 \mathrm{~h}$ under acidic conditions. The $\mathrm{HHD}$ formation was also possible in the presence of $\mathrm{HCO}_{2} \mathrm{H}$ as hydrogen donor with TOF $=6140 \mathrm{~h}^{-1}$ and $64 \%$ yield [151]. 
Within this context, de Vries presented a protocol for the one-pot synthesis of 2-hydroxy-3-methylcyclopent-2-enone (MCP) via ring opening of HMF to HHD in the presence of half-sandwich $\mathrm{Cp}^{*} \mathrm{Ir}(\mathrm{dpa}) \mathrm{Cl}$ (dpa=dipyridylamine) in $\mathrm{H}_{2} \mathrm{O} / \mathrm{KOH}$ at $120{ }^{\circ} \mathrm{C}$, 10 bar $\mathrm{H}_{2}$ and $2 \mathrm{~h}$. The MCP was isolated in 55\% yield. Interestingly, the presence of base promoted aldol condensation leading to MCP instead of the expected 3-(hydroxymethyl)cyc lopent-2-en-1-one (HCPEN) [152]. The subsequent hydrogenation of MCP towards 3-methyl-1,2-cyclopentanediol was also tested with Ru-MACHO-BH (0.5 mol\%) in THF at $100{ }^{\circ} \mathrm{C}, 20$ bar $\mathrm{H}_{2}$ affording $96 \%$ yield. Noteworthy, the use of this Ru-PNP catalyst for the direct ring opening of HMF diminished the yield of HHD to $5 \%$ under similar reaction conditions (Figure 6).

\section{Hydrodeoxygenation of Furanics}

Biodiesel and ethanol have been promoted over the past decade as a sustainable substitute for fossil fuels [153]. As result, there is a growing incentive to identify new strategies for converting non-edible biomass to biofuels. Among those examples, furanic derived fuels (or drop-in fuel compounds) also constitute a sustainable alternative to fossil-based products [154].

The upgrading of biomass-derived furanics to furanic biofuels is carried out by catalytic hydrogenation and hydrodeoxygenation (HDO) [155]. In this regards, the catalytic HDO of HMF or other chemical modifications allow the synthesis of more suitable liquid biofuels. In both types of reactions, the hydrogen atoms are added to the molecule to decrease the degree of unsaturation or cleave $\mathrm{C}-\mathrm{O}$ bonds.

In fact, FAL and 5-HMF, which are generated by the corresponding dehydration of C5 and C6 sugars in the acid hydrolysis of lignocellulose, produce 2-methylfuran (2-MF), and 2,5-dimethylfuran (DMF), as hydrodeoxygenation (HDO) products. The other drop-in fuels compounds include 2,5-dimethyltetrahydrofuran (DMTHF), 5-ethoxymethylfurfural (EMF), ethyl levulinate (EL), GVL, distillate range hydrocarbons and aromatic aviation fuel additive [156].

Thus, the selective HDO of HMF is a general approach to produce the liquid biofuel DMF, which has combustion properties comparable to those of gasoline, [157] representing an alternative fuel with many desirable characteristics that overcome the drawbacks of lowcarbon alcohols such as ethanol and $n$-butanol [158]. For example, DMF has the highest research octane numbers $(\mathrm{RON}=119)$ of the mono-oxygenated $\mathrm{C} 6$ compounds, while preserving a high energy density $\left(30 \mathrm{~kJ} \mathrm{~cm}^{-3}\right)$ and ideal boiling point $\left(92-95^{\circ} \mathrm{C}\right)$ [159]. In general, ethers can be blended into petroleum-derived diesel up to $17 \%$ with no adverse effects on engine performance and decreasing particulate emissions [160].

One of the most promising transportation biofuel is 5-ethoxymethylfurfural (EMF) with energy density of (30.3 MJ/L), which is similar to gasoline (31.3 MJ/L) and diesel (33.6 MJ/L) [161]. This chemical is usually synthesized from biomass sugars (glucose, fructose, or inulin) over an acid catalyst in ethanol. In comparison with the traditional hydrolysis, the use of the ethanolic system minimize the waste-water treatment and discharge [162]. The reported homogeneous catalysts for the synthesis of EMF include inorganic acids and soluble metal salts.

For instance, Liu reported the use of $\mathrm{SnCl}_{4} \cdot 5 \mathrm{H}_{2} \mathrm{O}, \mathrm{FeCl}_{3}$, and $\mathrm{CrCl}_{3} \cdot 6 \mathrm{H}_{2} \mathrm{O}$ for the production of EMF with yield up to 33\% [163]. Zhang and Deng reported the one-pot conversion of fructose into EMF using $\mathrm{FeCl}_{3}$ in the presence of ethanol-[BMIM] $\mathrm{Cl}$ as solvent. This methodology improved the production of EMF in $91 \%$ yield after $4 \mathrm{~h}$ at $100{ }^{\circ} \mathrm{C}$. Presumably, the ionic liquid stabilize HMF and improve the selectivity of the reaction [164]. HMF is often used as a precursor for liquid hydrocarbon fuels via the production of linear alkene aldol condensation and HDO producing hydrocarbons in the approximate molecular weight range for diesel and jet fuel [165].

HDO of sugars and furans have been reported with heterogeneous hydrogenation and hydrogenolysis catalytic systems. However, the homogeneous catalyst systems based on transition metal complexes is scarcely studied. The atom economy for the hydrogenation 
and HDO processes is extremely high, and only water is formed as byproduct [155]. However, the activation energies of the hydrogenation and HDO steps can lead to a mixture of partially hydrogenated products and intractable mixtures limiting its use [166]. The HDO of highly polar and reactive sugar-derived furans forces the use of a polar liquid reaction medium, such as $\mathrm{H}_{2} \mathrm{O}$. The high temperatures used for this process $\left(>150{ }^{\circ} \mathrm{C}\right)$ are required to trigger any dehydration or hydrolysis steps [167].

It is known that the selective hydrogenolysis of the hydroxymethyl moiety of HMF forms 5-methylfurfural (5-MF), which has potential applications as a fuel oxygenate and a chemical intermediate. Further reduction of 5-MF leads to 2,5-dimethylfuran (DMF) via 2-(hydroxymethyl)-5-methylfuran (HMMF). As a promising biofuel, DMF has similar physicochemical properties to gasoline and also a green solvent. It has also been demonstrated as a crucial chemical intermediate to produce $p$-xylene for terephthalate polymers [168].

Hydrogenation of the furan ring in DMF produces 2,5-dimethyltetrahydrofuran (DMTHF), which is a promising fuel oxygenate and a renewable substitute for tetrahydrofuran (Figure 7). Schlaf reported the use of the $\left[\left(4^{\prime}\right.\right.$-Ph-terpy) $\left.\mathrm{Ru}\left(\mathrm{H}_{2} \mathrm{O}\right)_{3}\right](\mathrm{OTf})$ catalyst and its iridium analogue $\left(4^{\prime}\right.$-Ph-terpy) $\operatorname{Ir}(\mathrm{OTf})_{3}$ for the conversion of DMF to hydrodeoxygenated products DMTHF and 2,5-hexanediol (2,5-HD), 2,5-hexanedione (2,5-HDO) and hexane in aqueous acidic medium at high temperature $\left(175-225^{\circ} \mathrm{C}\right)$ and 55 bar $\mathrm{H}_{2}$ [169]. However, the aqueous acidic medium and high temperatures eventually can decompose the catalysts. Depending on reaction conditions, the ruthenium system with $0.1 \mathrm{~mol} \%$ loading, leads to $2,5-\mathrm{HD}\left(69 \%\right.$ at $\left.175^{\circ} \mathrm{C}\right)$ or DMTHF $\left(80 \%\right.$ at $\left.200-225^{\circ} \mathrm{C}\right)$ with the concomitant generation of small amounts of 2-hexanone and hexane.

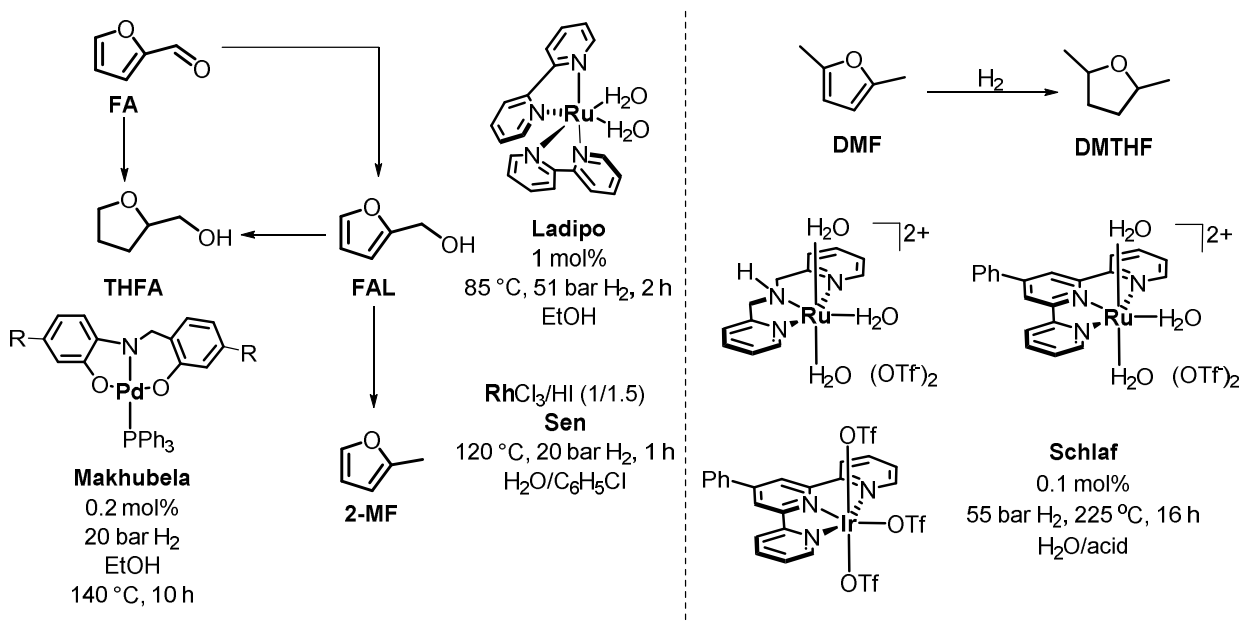

Figure 7. Catalytic HDO of HMF and catalyzed by transition metal complexes.

Both catalyst were deactivated by formation of unreactive bis-chelate complexes [M $\left(4^{\prime}-\right.$ Ph-terpy $\left.)_{2}\right]^{+}(\mathrm{M}=\mathrm{Ru}, \mathrm{Ir} ; n=2$ or 3$)$ diminishing the catalytic activity under HDO harsh reaction conditions. The same author evaluated the catalyst $\left[\mathrm{Ru}\left(2,2^{\prime}\right.\right.$-dipicolylamine $\left.)\left(\mathrm{OH}_{2}\right)_{3}\right]$ $(\mathrm{OTf})_{2}$ yielding $55 \%$ of 2,5-dimethyltetrahydrofuran in the presence of acid co-catalyst $\left(\mathrm{H}_{3} \mathrm{PO}_{4}\right)$ at $150{ }^{\circ} \mathrm{C}$.

Most of the intermediates and HDO products observed with homogeneous systems are limited to furfural. For instance, Sen and coworkers used $\mathrm{RhCl}_{3} / \mathrm{HI}(1 / 1.5)$ system to the direct conversion of xylose in a biphasic water/chlorobenzene mixture at $140{ }^{\circ} \mathrm{C}$ and 20 bar $\mathrm{H}_{2}$, producing $80 \%$ yield of 2-MF accompanied with the production of $\mathrm{I}_{2}$ [170].

In other attempt, Ladipo showed a cascade hydrodeoxygenation reaction of FAL employing an active $\mathrm{Ru}(\mathrm{II})$-bis(diimine) complex. The catalyst cis-[ $\left.\mathrm{Ru}\left(6,6^{\prime}-\mathrm{Cl}_{2} \mathrm{bpy}\right)_{2}\left(\mathrm{OH}_{2}\right)_{2}\right]$ $(\mathrm{BArF})_{2}(1 \mathrm{~mol} \%)$ displayed good selectivity leading from FAL into FA $(93 \%)$ at $85^{\circ} \mathrm{C}$, 51 bar $\mathrm{H}_{2}$ and $2 \mathrm{~h}$. Further transformation of FA at $130{ }^{\circ} \mathrm{C}$, led to a very useful chemical precursor THFA (99\%) via hydrogenation. The subsequent hydrogenolysis yielded 2-MF under similar reaction conditions [116]. 
Makhubela reported a Pd(II)-Schiff base complex for the conversion of FAL towards FA $(88 \%)$ and THFA as a second product (12\%). The reaction was carried out using $0.2 \mathrm{~mol} \%$

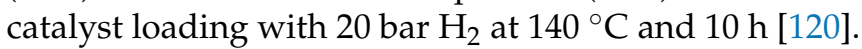

Under catalytic conditions, the ring opening of furfuryl alcohol can happen in two sides of the furanic ring. The reductive ring opening next to the hydroxyl group leads to 1,5pentanediol formation, whereas the opposite side ring opening gives 1,2-pentanediol. [53] There is not such a catalytic process to control the selectivity of this reaction, because the chemical environments of the two furanic $\mathrm{C}-\mathrm{O}$ bonds are similar. The opposite is true for the hydrogenation tetrahydrofurforyl alcohol, where the formation of 1,5-pentanediol is favored.

\section{Oxidative Transformations}

Oxidative transformation of HMF lead to 2,5-diformylfuran (DFF), and / or 2,5-furandi carboxylic acid (FDCA). In this regard, the selective oxidation of HMF to the industrial precursor 2,5-diformylfuran (DFF) is relevant for the synthesis of pharmaceuticals, fungicides, and functional polymers [171]. In fact, selective oxidation reactions of HMF are currently viewed as attractive routes to 2,5-furandicarboxylic acid (FDCA) and/or 2,5-diformylfuran (DFF) and 5-formyl-2-furancarboxylic acid (FFCA), monomers for furan-containing polymers and materials with special properties [172].

While a variety of oxidants have been used for oxidation of HMF to FDCA and DFF, only few reports describe catalytic oxidations of HMF with oxygen or air, the most economical oxidants [173]. Recently, much progress has been made in the development of homogeneous catalytic systems for this transformation (Figure 8). For example, Corma reported the use of immobilized vanadyl-pyridine complexes affording $82 \%$ conversion and high selectivity $(\geq 99 \%)$ at $130{ }^{\circ} \mathrm{C}[37,174]$.

In general, the efficient and selective formation of DFF can be achieved by using vanadium-catalyzed systems. $\mathrm{Xu}$ reported a homogeneous catalytic mixture of $\mathrm{Cu}\left(\mathrm{NO}_{3}\right)_{2} /$ $\mathrm{VOSO}_{4}(2 \mathrm{~mol} \%, 1: 1$ ratio) for the selective oxidation of HMF to DFF under mild reaction conditions $\left(25-80{ }^{\circ} \mathrm{C}, 1.5 \mathrm{~h}, 10\right.$ bar $\left.\mathrm{O}_{2}\right)$ in $\mathrm{CH}_{3} \mathrm{CN}[175,176]$. The inorganic catalyst is easily removed from the reaction mixture. Nevertheless, the instability and high cost of HMF limit the production of DFF [177]. A sustainable option is the catalytic conversion of carbohydrates to DFF without further purification of HMF.

The commercialization of FDCA produced from fructose-derived HMF is one example of the successful use of biomass [178]. In this industrial process, fructose is dehydrated in methanol solvent to the HMF analogue methoxymethylfurfural (MMF). Then, MMF is oxidized to FDCA using the homogeneous oxidation catalyst [179].

Moreover, FDCA has significantly wide attention particularly as a substitute of petrochemical-derived terephthalic acid in the synthesis of useful polymers [180]. In fact, FDCA can undergo coupling with mono-ethylene glycol to produce polyethylene furanoate (PEF), a green replacement for polyethylene terephthalate (PET) [181]. Even though, several methods for the synthesis of FDCA have been reported such as electrochemical oxidation and biocatalytic oxidation, synthesis of FDCA is mainly carried out via catalytic methods using heterogeneous or homogeneous catalysts.

Thus, HMF has been oxidized with $\mathrm{O}_{2}$ to FDCA in the presence of heterogeneous Pt catalysts with stoichiometric amounts of alkali [182,183] and to DFF with TEMPO radicals [183] or supported vanadium catalysts [157]. On the other hand, homogeneous catalytic system for the synthesis of FDCA has been scarcely reported when compared to heterogeneous catalysts. 


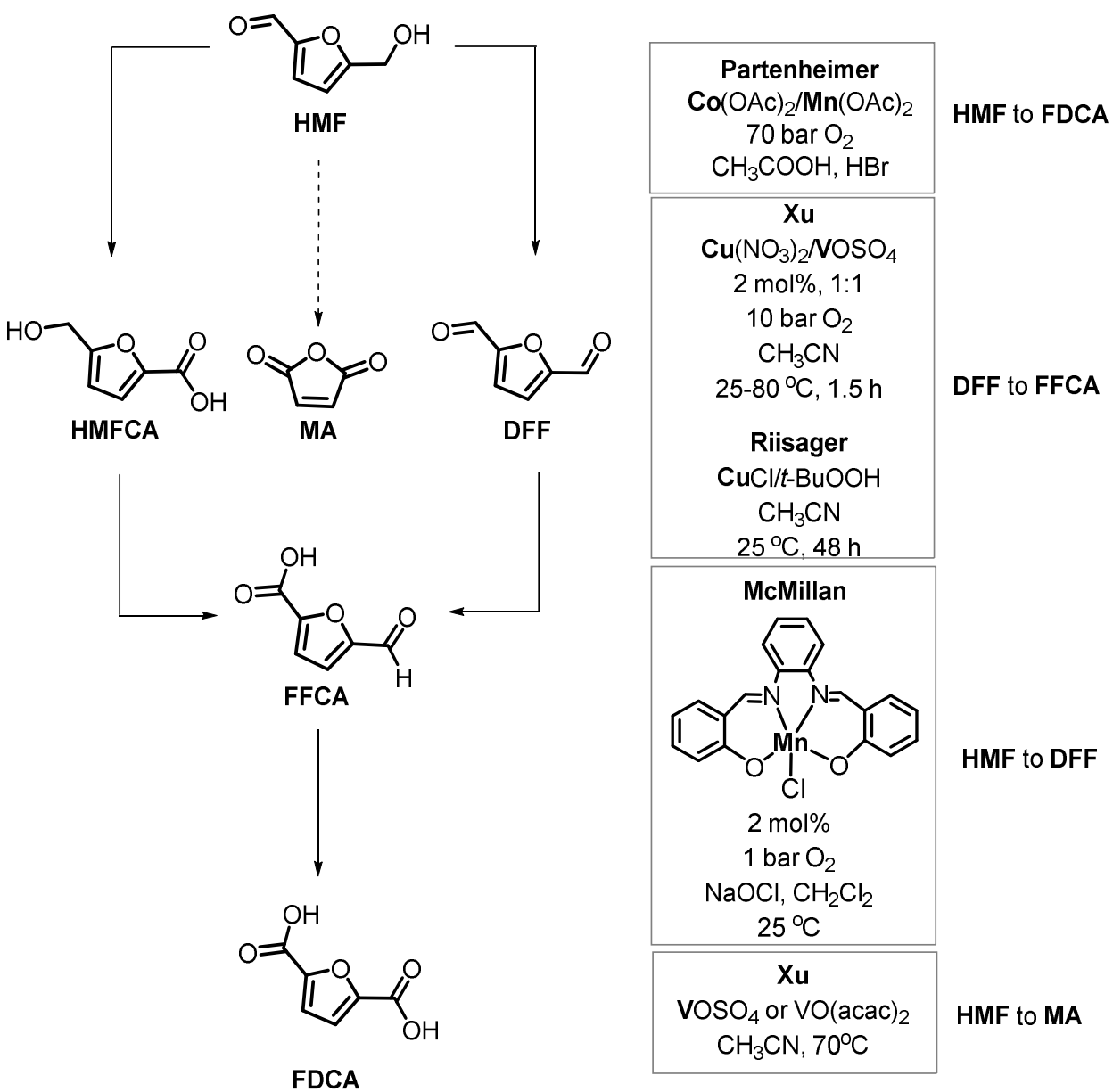

Figure 8. Methods of oxidation of furanics.

Partenheimer described the first examples of aerobic HMF oxidation reactions, catalyzed with homogeneous metal/bromide systems. The aerobic oxidation of HMF to FDCA was achieved at $125^{\circ} \mathrm{C}$ under 70 bar air pressure in acetic acid solvent using $\mathrm{Co}(\mathrm{OAc})_{2}$, $\mathrm{Mn}(\mathrm{OAc})_{2}$, and $\mathrm{HBr}$ as the catalysts, commonly known as the Amoco Mid-Century (MC) catalyst [184]. They observed that HMF can be oxidized to DFF or 2,5-furandicarboxylic acid with high selectivity by tuning the reaction conditions. The oxidation of HMF with the MC catalyst proceeded via the formation of peroxyl radical in the chain propagation step.

The peroxyl radicals were formed through the abstraction of $\mathrm{H}$-atom of HMF by the bromide radical, generated in the catalytic cycle by the oxidation of $\mathrm{HBr}$ with $\mathrm{Co}$ (III) or $\mathrm{Mn}(\mathrm{III})$, followed by reaction of aryl alkyl radical with $\mathrm{O}_{2}$. Although both hydroxymethyl and aldehyde groups of HMF could be simultaneously oxidized, the authors proposed that the $\mathrm{OH}$ group of $\mathrm{HMF}$ is selectively oxidized by dioxygen and metal/bromide catalysts to obtain 2,5-diformylfuran (DFF) in 57\% isolated yield. HMF can be also oxidized via a network of identified intermediates to 2,5-furandicarboxylic acid (FDCA) in 60\% yield. For comparison, benzyl alcohol gives benzaldehyde in $80 \%$ using the same catalytic system.

Similarly, Abu-Omar reported the use of $\mathrm{Co}(\mathrm{OAc})_{2} / \mathrm{Zn}(\mathrm{OAc})_{2} / \mathrm{NaBr}$ mixture for the aerobic oxidation of HMF into FDCA [185]. DFF was observed as the only oxidation product without an acid additive, but FDCA was obtained in a yield of $60 \%$ with trifluoroacetic acid as an additive. McMillan proposed an efficient methodology for the efficient oxidation of HMF to DFF using a Mn(III)-salen ( $2 \mathrm{~mol} \%$ ) complex in the presence of $\mathrm{NaOCl}$ as oxidant under 1 bar $\mathrm{O}_{2}$ in $\mathrm{CH}_{2} \mathrm{Cl}_{2}$ at $25{ }^{\circ} \mathrm{C}$. The yield of the expected product was improved up to $89 \%$ [186].

The use of other oxidant such as tert-butyl hydroperoxide $(t-\mathrm{BuOOH})$ was also studied for the transformation of HMF into FDCA. Riisager reported the oxidation of HMF into 
FDCA in $\mathrm{CH}_{3} \mathrm{CN}$ with $t$-BuOOH as the oxidant and copper salts as catalyst [187]. The use of $\mathrm{CuCl}$ together with $\mathrm{LiBr}$ as the additive yielded $43 \%$ of FDCA after $48 \mathrm{~h}$ at room temperature, whereas using $\mathrm{CuCl}_{2}$ as the catalyst afforded $45 \%$ without additive.

Another important chemical intermediate derived from HMF is maleic anhydride (MA), which is mainly used for the synthesis of unsaturated polyester resins [188]. In fact, FA is the starting material for the production of maleic anhydride or maleic acid, via oxidation. $\mathrm{Xu}$ and co-workers reported the selective oxidation of HMF to MA using vanadyl complexes such as $\mathrm{VOSO}_{4}$ and $\mathrm{VO}(\mathrm{acac})_{2}$ without proceeding through any oxidized furan intermediates [189]. The reaction was performed at $70{ }^{\circ} \mathrm{C}$ in $\mathrm{CH}_{3} \mathrm{CN}$ affording $52 \%$ yield of MA. To the best of our knowledge, the heteropolyacid catalyst $\mathrm{H}_{3} \mathrm{PMo}_{12} \mathrm{O}_{40}$ modified with $\mathrm{VO}(\mathrm{acac})_{2}$ have shown the best catalytic performance towards the formation of MA in $56 \%$ yield [190,191].

Interestingly, $\mathrm{Pd}(\mathrm{OAc})_{2}$ catalyst showed a $16 \%$ yield to furoic acid, while only traces of this compound were observed over other metal catalysts. However, the major competitive process for the selective oxidation is the polymerization of furfural to generate resins under the oxidative conditions. The by-product of furfural oxidation in gas phase is furan. In fact, furan is the first intermediate in the mechanism of the furfural oxidation and an important intermediate in chemical industry. Hence, even though it cannot be produced directly from biomass, it is produced from FA [192].

\section{Other Chemical Transformation of Furanics}

\subsection{Catalytic Carbonyl Coupling of Furanics with Nucleophilic Nitrogen Sources}

The introduction of nitrogen-containing functionalities in biomass-derived compounds, add value and expand their industry applicability [193]. In fact, reductive amination of HMF constitutes an important basic route for the sustainable production of nitrogencontaining compounds from biorenewables [194]. HMF can be converted into valuable N-containing furanyl compounds through the reductive amination of aldehyde groups (Figure 9).

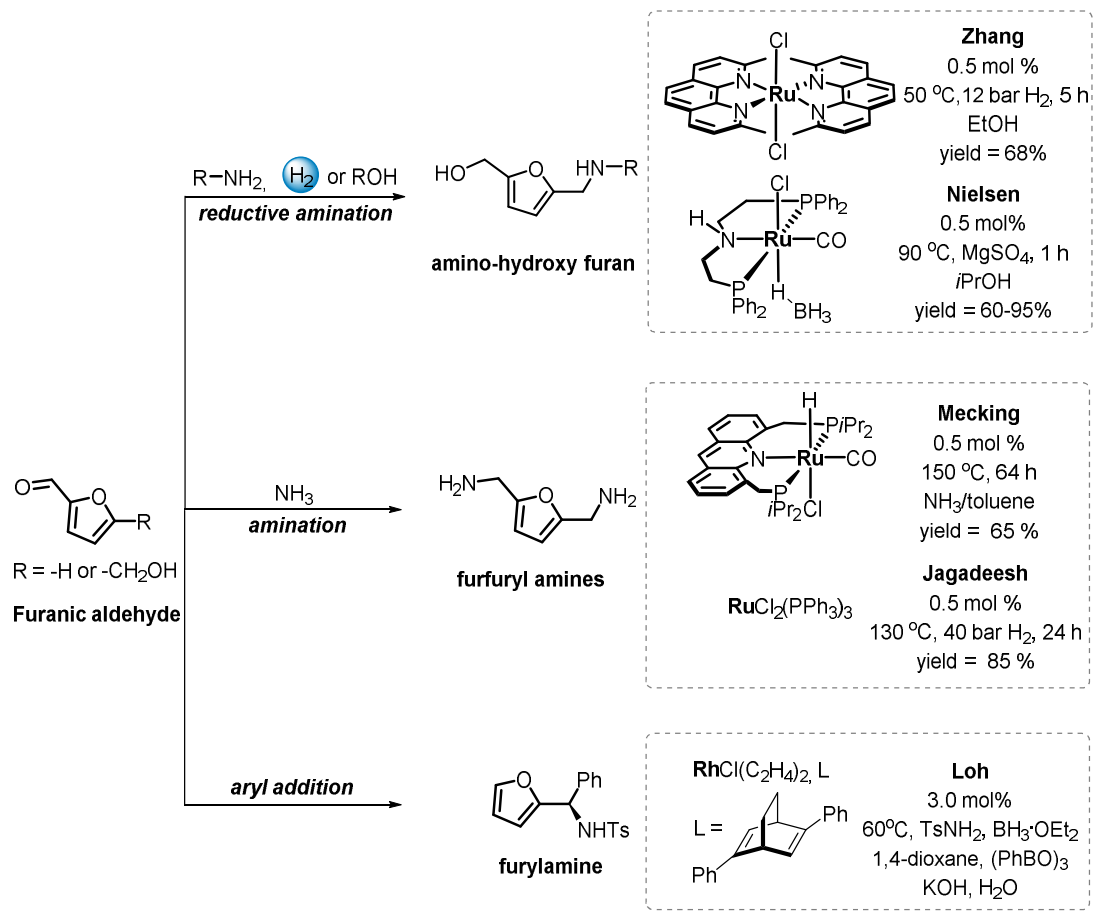

Figure 9. Synthesis of $\mathrm{N}$-containing building blocks via reductive amination of furanics.

N-Substituted 5-(hydroxymethyl)-2-furfuryl amines have a wide application in pharmaceutical industry, e.g., for the production of calcium antagonists, muscarinic agonists, cholinergic agents, and carcinogenesis inhibitors [195]. These structures are conventionally 
prepared by a Mannich-type reaction starting from FAL or FA with primary amines under harsh reaction conditions [196]. However, the C2 aldehyde group makes the C5 position of furan ring difficult for addition because of the deactivating effect [197].

The use of a metal catalysts is a prerequisite for efficient reductive amination via two reaction routes, including initial reduction to alcohols followed by amination or first the amination to form coupled imines and subsequent hydrogenation [198]. Zhang reported an optimal Ru-based catalyst $\mathrm{Ru}(\mathrm{DMP})_{2} \mathrm{Cl}_{2}$, (DMP) dichlorobis(2,9-dimethyl-1,10phenanthroline)ruthenium(II) for the reductive amination of HMF with aniline. N-phenyl5-(hydroxymethyl)-2-furfuryl amine was obtained in $68 \%$ yield at $50{ }^{\circ} \mathrm{C}$ with 12 bar $\mathrm{H}_{2}$ in $5 \mathrm{~h}$.

$\mathrm{H}_{2}$ is employed as the reducing agent, which improves the atom economy of the reaction in the presence of bio-based $\mathrm{EtOH}$ as solvent making the process more sustainable [199]. Particularly, the catalytic performance of $\mathrm{Ru}(\mathrm{DMP})_{2} \mathrm{Cl}_{2}$ was more effective at $60^{\circ} \mathrm{C}$ with a sharp increase in the yield (up to $98 \%$ ). Hence, this catalytic system was efficient for synthesizing a number of new aminomethyl-hydroxymethylfurans with primary and secondary amines.

Homogeneous catalysis can promote the direct amination and reductive amination of furanic aldehydes and its derived alcohols into polymers. Mecking described the reductive amination of HMF with ammonia in the presence of the Milstein Ru-acridine diphosphine complex (Figure 9) to furfuryl diamines. This reaction led to the desired product 2,5bis(aminomethyl)furan in $65 \%$ yield at $150{ }^{\circ} \mathrm{C}$ after $4 \mathrm{~h}$ with $2.5 \mathrm{bar}$ of $\mathrm{H}_{2}$ [200]. The monoamine derivative 2,5-bis(aminomethyl)furan is also an important monomer for the manufacture of long-chain polyamides. Bis(hydroxylmethylfurfuryl)amine is a key furanbased monomer for the synthesis of functional biopolymers, which can be synthesized from the reductive amination of HMF.

Thus, the reductive amination of HMF with $n$-heptylamine was achieved with the already described $\mathrm{Ru}(\mathrm{DMP})_{2} \mathrm{Cl}_{2}$ catalyst. The bis(hydroxylmethylfurfuryl)amine was obtained in $90 \%$ yield at $110{ }^{\circ} \mathrm{C}$ with 0.2 bar of $\mathrm{H}_{2}$ and $12 \mathrm{~h}$ [201]. The condensation of HMF with the alkylamine followed by hydrogenation forms the amine, which yielded bis(hydroxylmethylfurfuryl)amine after subsequent addition reaction, dehydration and hydrogenation. The authors claimed through comparison experiments and X-ray photoelectron spectroscopy analysis that the synergistic effect of Ru (II) and DMP ligand was accountable for the remarkable catalytic performance of the Ru-based catalyst.

Furfurylamines derived from the selective reductive amination of furfurals exhibits diverse applications in the industry, including the preparation of pharmaceutical, such as antiseptic agents, antihypertensives, and diuretics as well as agrochemicals, pesticides, and synthetic resins and polymers [202]. The synthesis of furfurylamines from furfurals by reductive amination has been investigated using various reducing agents and catalysts. Reducing agents such as hydrogen gas, silanes, borohydrides, and formic acid have been reported in the literature.

Jagadeesh described the use of $\mathrm{RuCl}_{2}\left(\mathrm{PPh}_{3}\right)_{3}$ for the reductive amination of furfural with ammonia, providing $85 \%$ yield of furfurylamine in $24 \mathrm{~h}$ and $130{ }^{\circ} \mathrm{C}$ under 40 bar of $\mathrm{H}_{2}$ [203]. Noteworthy, the Ru-hydride species $\mathrm{RuH}_{2}\left(\mathrm{PPh}_{3}\right)_{3}$ or $\mathrm{RuHCl}\left(\mathrm{PPh}_{3}\right)_{3}$, formed in the reaction served as active catalytic species reacting with formed furfuryl imine. Recently, Nielsen reported an efficient, chemoselective, and base free transfer hydrogenation of furfural to furfuryl amines employing Ru-MACHO-BH as catalyst and $i \mathrm{PrOH}$ as $\mathrm{H}$-donor. A relatively low catalyst loading $(0.5 \mathrm{~mol} \%)$ in the presence of $\mathrm{MgSO}_{4}$ as drying agent resulted in full conversion of furfural to furfuryl amines at $90{ }^{\circ} \mathrm{C}$ after $1 \mathrm{~h}$ [204]. The general applicability of this method was tested with various amines affording moderate to excellent yield.

Loh described the asymmetric arylation of FAL in the presence of a rhodium-catalyst $\left[\mathrm{RuCl}\left(\mathrm{C}_{2} \mathrm{H}_{4}\right)\right]_{2} \mathrm{~L}(\mathrm{~L}=(1 R, 4 R)-2,5-$ Diphenylbicyclo[2.2.2]octa-2,5-diene) to produce furylamine with $97 \%$ yield and $99 \%$ ee [205]. This methodology provides highly functionalized amines, which can be converted to piperidone-based pharmaceuticals. 


\subsection{Functionalization of Furanics and C-C Bond Formation}

Furan-derived compounds are accessible intermediates for many other transformations in organic synthesis and constitute structural motifs in natural products or biologically drug molecules $[206,207]$. For example, Sheldon reported the palladium-catalyzed carbonylation of $\mathrm{HMF}$ with $\mathrm{PdCl}_{2} / \mathrm{TPPTS}$ system in water at $70{ }^{\circ} \mathrm{C}$ and 5 bar $\mathrm{CO}$ (Figure 10) [208]. In addition to 4-formyl-2-furancarboxylic acid, they observed MF as byproduct from the reduction of $\mathrm{HMF}$.

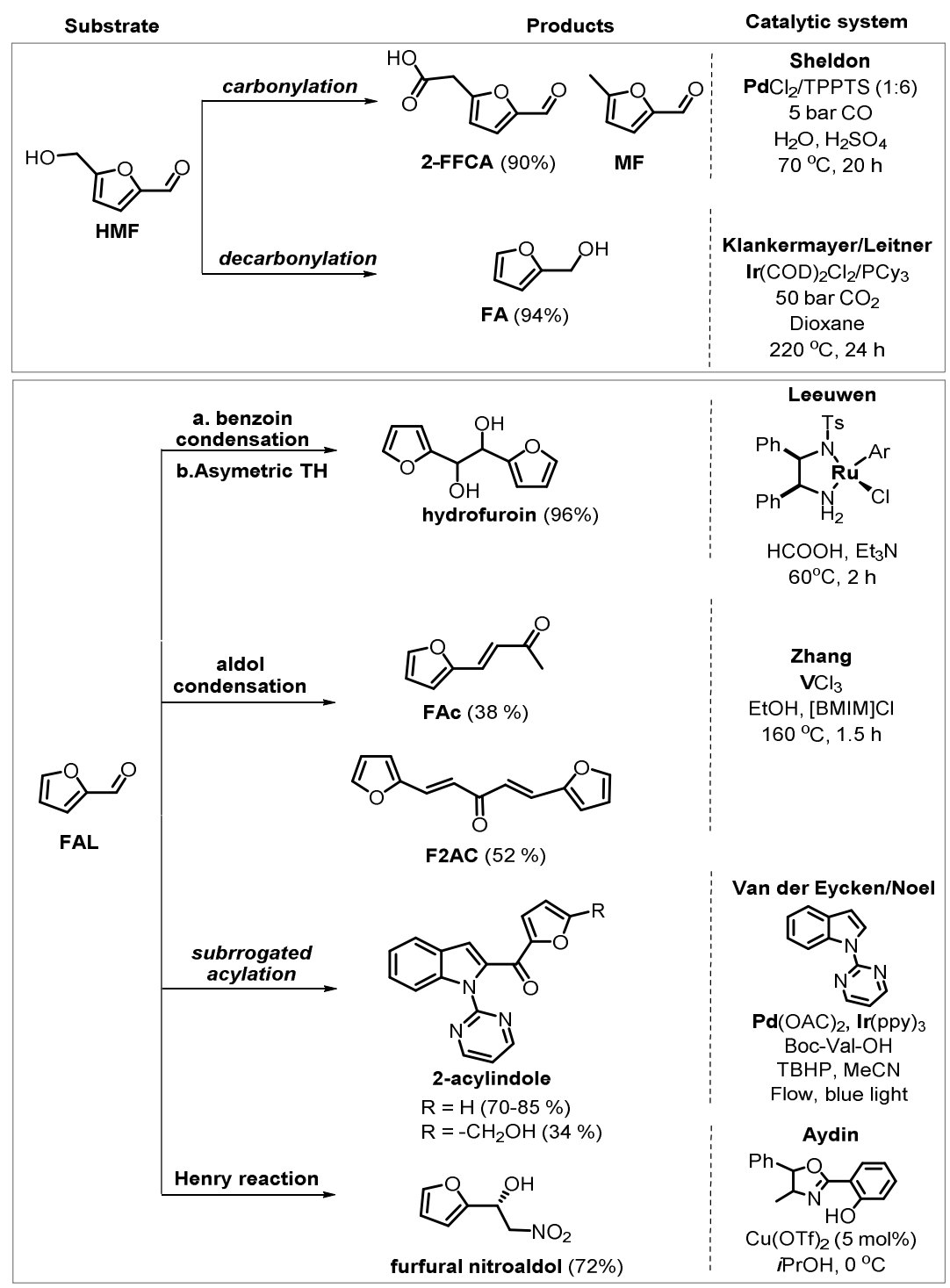

Figure 10. Biomass derived furanic-based intermediate for drugs syntheses.

The decarbonylation/reduction of HMF was explored by Klankermayer and Leitner [209]. The reaction was carried out with a catalytic system $\operatorname{IrCl}(\operatorname{cod})_{2}(\operatorname{cod}=1,5-$ cyclooctadiene) as the metal precursor in the presence of a phosphine ligand (PCy3) in boiling 1,4-dioxane resulting in $41 \%$ conversion with $97 \%$ selectivity towards DHMF after $48 \mathrm{~h}$. Interestingly, the addition of $\mathrm{CO}_{2}$ increased the conversion up to $99 \%$, suppressing the formation of humins. The substitution of solvent with THFA converted all the mixture into a single product stream of THFA.

The elongating of carbon chains of biomass-derived furanic compounds to produce fuel precursors or furan-based platform molecules can be achieved using several strategies, including aldol condensation [210,211], hydroxyalkylation/alkylation [212,213], Knoevenagel condensation [214], benzoin condensation [215], and Diels-Alder reaction [216]. 
The benzoin condensation of furfural is a well-known process for the synthesis of furoin. This class of compound is relevant for the preparation of alkane fuels via the HDO process. Leeuwen described the asymmetric reduction of the carbonyl group of furoin with a chiral catalyst $\mathrm{RuCl}(p$-cymene $)((S, S)$-TsDPEN $)(0.5 \mathrm{~mol} \%)$ to produce hydrofuroin with a $96 \%$ yield [217].

In general, aldol condensation reactions involve the enolization of a carbonyl group containing an $\alpha-\mathrm{C}-\mathrm{H}$ followed by $\mathrm{C}-\mathrm{C}$ coupling with another carbonyl and subsequent dehydration. Some homogeneous catalysts have been successfully applied in the synthesis of diesel-fuel-range multi-carbon precursors via aldol condensation. For instance, Zhang reported various metal chlorides catalysts, such as $\mathrm{NiCl}_{2}, \mathrm{CoCl}_{2}, \mathrm{CrCl}_{3}, \mathrm{VCl}_{3}$, and $\mathrm{FeCl}_{3}$, for the aldol condensation of furfural with acetone in [BMIM] Cl (1-butyl-3-methylimidazolium

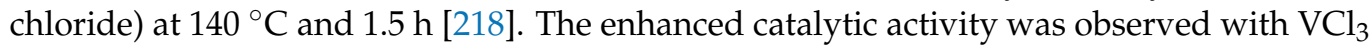
in the presence of ethanol, giving a $38 \%$ yield of furfurylideneacetone (FAc) and a $52 \%$ yield of (2-furanyl)-1,4-pentadien-3-one (F2Ac) at $160^{\circ} \mathrm{C}$ and $1.5 \mathrm{~h}$. Apparently, the acetal reaction of furfural with ethanol reduced the formation of side reactions of furfural.

Van der Eycken and Noël used HMF as acyl surrogates for the direct C-2 acylation of indoles at ambient temperature via dual photoredox/transition-metal catalysis in both batch and flow conditions [219]. The reaction was carried out in the presence of $\mathrm{Pd}(\mathrm{OAc})_{2}(10 \mathrm{~mol} \%)$, fac-[Ir(ppy) 3$],(2 \mathrm{~mol} \%), \mathrm{N}$-(tert-butoxycarbonyl)-L-valine (Boc-Val$\mathrm{OH}, 20 \mathrm{~mol} \%)$ in $\mathrm{CH}_{3} \mathrm{CN}(0.1 \mathrm{M})$ under argon, and exposed to light source for $24 \mathrm{~h}$ at $25^{\circ} \mathrm{C}$. Thus, the heteroatomic aldehydes, such as FAL and 2-thenaldehyde (TA), led to the corresponding 2-acylindole with a relatively moderate yield (68-85\%). Interestingly, HMF showed low reactivity and a lower yield ( $34 \%)$. Presumably, this detrimental effect is due to the poor compatibility of the hydroxymethyl group with an oxidative single electron transfer pathway.

Finally, Aydin described the asymmetric Henry reaction of FAL with nitromethane catalyzed by $\mathrm{Cu}(\mathrm{OTf})_{2}(5 \mathrm{~mol} \%)$ in the presence of an excess of a chiral oxazoline base ligand and $\mathrm{PrOH}$ at $0{ }^{\circ} \mathrm{C}$. The product furfural nitroaldol was isolated with a $72 \%$ yield and $80 \% \mathrm{ee}$. This $\beta$-nitro alcohol can be converted into other key building block molecules of natural products or pharmaceuticals [220].

\subsection{Undirected $\mathrm{C}-\mathrm{H}$ Activation}

The catalytic activation of aromatic $\mathrm{C}-\mathrm{H}$ bonds leading to the formation of a $\mathrm{C}-\mathrm{C}$ bond is extremely relevant for chemical and pharmaceutical industries. In this regard, furans constitute key substrates for the synthesis of functionalized synthons. For example, Reiser and coworkers explored the transformation of furfuryl ester to cyclopropane in $36 \%$ yield and $91 \%$ ee employing a chiral CuBox catalyst $\mathrm{Cu}(\mathrm{OTf})_{2} \mathrm{iPr}-\mathrm{Box}$ (Figure 11$)$. In general, cyclopropanes are valuable synthetic building blocks in organic synthesis for the construction of natural products and drugs [221].

Fujiwara reported Pd-catalyzed intermolecular dehydrogenative Heck reactions of furans with activated olefins in the presence of $\mathrm{Pd}(\mathrm{OAc})_{2}$ giving styrene-type products with a $75 \%$ yield with catalyst loadings as low as $0.5 \mathrm{~mol} \%$ in $\mathrm{AcOH}$-dioxane [222]. Since then, other systems have been reported to increase the TON with various oxidants, additives and solvents.

Hartwig reported the Ir-catalyzed oxidative coupling of furans with unactivated olefins to produce branched vinylfurans in the presence of a second alkene as the hydrogen acceptor [223]. The catalytic system $\operatorname{Ir}(\mathrm{coe}){ }_{2} \mathrm{Cl}_{2}$ complex (2 mol\%) and the air-stable bisphosphine ligand $( \pm$ )-TMS-SEGPHOS ( $4 \mathrm{~mol} \%$ ) were combined to carry out the reaction at $50{ }^{\circ} \mathrm{C}$ for $24 \mathrm{~h}$ in tert-butylethylene (TBE) as a sacrificial hydrogen acceptor. Higher yields (up to $99 \%$ ) and selectivities were reported with furans containing electron-donating groups at C-2 on the furan. 

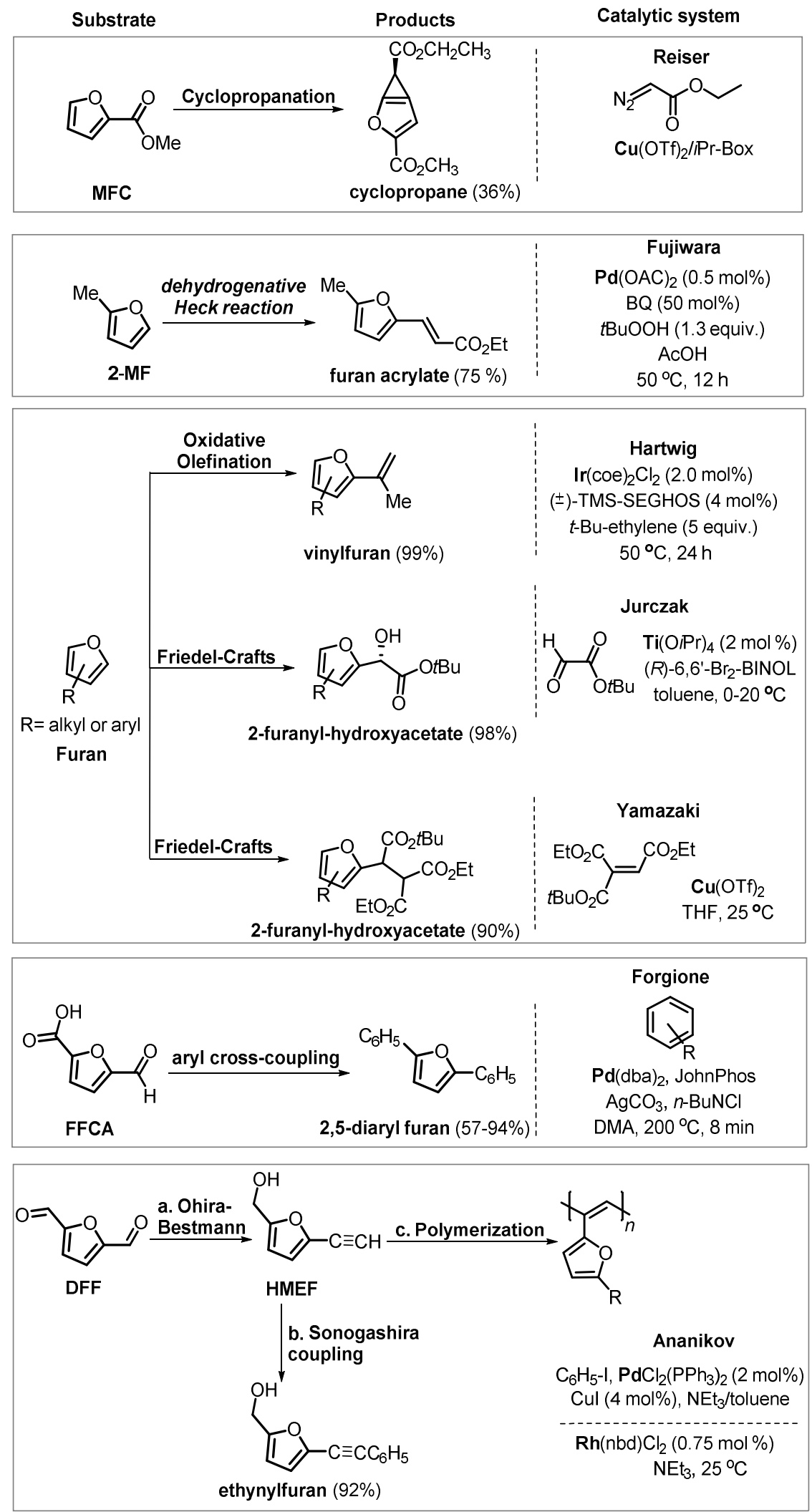

Figure 11. Catalytic functionalization of furanics in the presence of homogeneous catalytic systems.

Other synthetic methodologies for the production of bio-based synthons, such as 2 -furanyl-hydroxyacetates, have been reported. For example, Jurczak published examples of efficient Friedel-Crafts reactions of a series of furans with alkyl glyoxylates promoted 
by a 6,6'-dibromo-BINOL/Ti(IV) complex (2-5 mol\%) in toluene at $20^{\circ} \mathrm{C}$ affording up to $98 \%$ yields of 2-furanyl-hydroxyacetates with high enantioselectivity $(90-97 \% \mathrm{ee})$ [224]. Yamazaki also described the Friedel-Crafts process using $\mathrm{Cu}(\mathrm{OTf})_{2}(10 \mathrm{~mol} \%)$ in THF at $25{ }^{\circ} \mathrm{C}$ [225]. The reaction gave yields of up to $90 \%$ with $60 \%$ ee for the substituted furan.

Forgione described the modification of biomass-derived 2,5-furandicarboxylic acid to produce 2,5-diaryl furans through the highly regioselective decarboxylative crosscoupling reaction with $\mathrm{Pd}(\mathrm{dba})_{2}$ with high catalyst loadings $(15 \mathrm{~mol} \%)$ in dimethylformamide (DMF) [226]. The addition of silver-containing base, $\mathrm{Ag}_{2} \mathrm{CO}_{3}$ (1.5 equiv) and (2-biphenylyl)di-tert-butylphosphine (JonhPhos) increased the yield to $80 \%$ at $200{ }^{\circ} \mathrm{C}$. The same approach was applied for the synthesis of the muscle relaxant dantrolene from HMF [227].

Terminal alkynes are important precursors of substituted polyacetylenes, which exhibit unique optical, mechanical, magnetic, and electrical properties [228]. The conventional alkynylation of aldehydes requires harsh basic conditions, making the process unsuitable for HMF. Ananikov established that an alternative to, e.g., the Corey-Fuchs or the SeyferthGilbert reactions, is the Sonogashira coupling of 2-hydroxymethyl-5-ethynylfuran (HMEF) with iodobenzene in the presence of $\mathrm{PdCl}_{2}\left(\mathrm{PPh}_{3}\right)(2 \mathrm{~mol} \%)$ at $60{ }^{\circ} \mathrm{C}$ overnight. The corresponding alkyne was produced at a $92 \%$ yield [229]. The polymerization of terminal alkynes is feasible in the presence of Rh-based catalytic systems. Thus, ethynyl derivatives derived from $\mathrm{HMF}$ were subjected to the polymerization reaction catalyzed by $\mathrm{Rh}(\mathrm{nbd}) \mathrm{Cl}_{2}$ (nbd=norbornadiene) $(0.75 \mathrm{~mol} \%)$ in triethylamine at $25^{\circ} \mathrm{C}$.

\section{Conclusions}

Biomass is the most accessible and low-cost economical solution for the production of sustainable transportation fuels as well as the only non-petroleum route to organic molecules for the manufacture of bulk and fine chemicals. However, designing a sustainable and cost-effective biorefinery remains a great challenge. The upgrading of biomass feedstock involves chemical transformations, such as hydrolysis, dehydration, isomerization, oxidation, hydrogenation, deoxygenation, and hydrodeoxygenation.

Effective catalysts are critical for developing efficient and clean chemical processes in industry. Thus, the design of catalysts for such transformations require new classes of homogeneous catalyst that are compatible with the highly oxygenated nature of biomass. In addition, low-temperatures $\left(<200^{\circ} \mathrm{C}\right)$, the aqueous-phase processing of sugars, the development of effective homogeneous catalysts with earth-abundant metals, and reductions in the use of harmful reagents are desired.

The use of furanic molecules (HMF, FAL, BHMF, DFF, and FDCA) as starting materials for synthetic applications is highly attractive for the scientific community and for industrial applications. Over the past years, significant advances have been reported for the production of biofuels with new catalysts. The highlighted examples in this review demonstrated the range of potential chemical transformations that can occur for biomass-derived platform molecules employing homogeneous catalysis. With the widespread application of these synthetic methodologies, further progress is expected in this field.

Author Contributions: Conceptualization, R.P.; writing-original draft preparation, R.P. and S.K.; writing-review and editing, R.P., S.K. and M.N.; visualization, R.P., S.K. and M.N.; project administration, M.N.; funding acquisition, M.N. All authors have read and agreed to the published version of the manuscript.

Funding: The authors thank VILLUM FONDEN (19049) and Novo Nordisk Foundation (NNF20OC0 064560) for funding this research.

Conflicts of Interest: The authors declare no conflict of interest. 


\section{References}

1. Yang, L.; Wang, X.-C.; Dai, M.; Chen, B.; Qiao, Y.; Deng, H.; Zhang, D.; Zhang, Y.; Villas Bôas de Almeida, C.M.; Chiu, A.S.F.; et al. Shifting from Fossil-Based Economy to Bio-Based Economy: Status Quo, Challenges, and Prospects. Energy 2021, $228,120533$. [CrossRef]

2. Nelson, A.E. Fundamentals of Industrial Catalytic Processes, 2nd Edition. C. H. Bartholomew and Robert J. Farrauto John Wiley and Sons, Hoboken, NJ, 966 pp., 2006. Can. J. Chem. Eng. 2008, 85, 127-128. [CrossRef]

3. Wilson, K.; Lee, A.F. Catalyst Design for Biorefining. Philo. Trans. R. Soc. A 2016, 374, 20150081. [CrossRef]

4. Antonetti, C.; Licursi, D.; Raspolli Galletti, A.M. New Intensification Strategies for the Direct Conversion of Real Biomass into Platform and Fine Chemicals: What Are the Main Improvable Key Aspects? Catalysts 2020, 10, 961. [CrossRef]

5. Lin, L.; Han, X.; Han, B.; Yang, S. Emerging Heterogeneous Catalysts for Biomass Conversion: Studies of the Reaction Mechanism. Chem. Soc. Rev. 2021, 50, 11270-11292. [CrossRef]

6. Walker, T.W.; Motagamwala, A.H.; Dumesic, J.A.; Huber, G.W. Fundamental Catalytic Challenges to Design Improved Biomass Conversion Technologies. J. Catal. 2019, 369, 518-525. [CrossRef]

7. Deuss, P.J.; Barta, K.; de Vries, J.G. Homogeneous Catalysis for the Conversion of Biomass and Biomass-Derived Platform Chemicals. Catal. Sci. Technol. 2014, 4, 1174-1196. [CrossRef]

8. Sordakis, K.; Tang, C.; Vogt, L.K.; Junge, H.; Dyson, P.J.; Beller, M.; Laurenczy, G. Homogeneous Catalysis for Sustainable Hydrogen Storage in Formic Acid and Alcohols. Chem. Rev. 2018, 118, 372-433. [CrossRef] [PubMed]

9. Piccirilli, L.; Lobo Justo Pinheiro, D.; Nielsen, M. Recent Progress with Pincer Transition Metal Catalysts for Sustainability. Catalysts 2020, 10, 773. [CrossRef]

10. Crabtree, R.H. An Organometallic Future in Green and Energy Chemistry? Organometallics 2011, 30, 17-19. [CrossRef]

11. Dixneuf, P.H. Organometallics for Green Catalysis, 1st ed.; Springer: Cham, Switzerland, 2019; ISBN 978-3-030-10954-7.

12. Bender, T.A.; Dabrowski, J.A.; Gagné, M.R. Homogeneous Catalysis for the Production of Low-Volume, High-Value Chemicals from Biomass. Nat. Rev. Chem. 2018, 2, 35-46. [CrossRef]

13. Dahiya, S.; Katakojwala, R.; Ramakrishna, S.; Mohan, S.V. Biobased Products and Life Cycle Assessment in the Context of Circular Economy and Sustainability. Mater. Circ. Econ. 2020, 2, 7. [CrossRef]

14. Yuan, H.; Liu, H.; Du, J.; Liu, K.; Wang, T.; Liu, L. Biocatalytic Production of 2,5-Furandicarboxylic Acid: Recent Advances and Future Perspectives. Appl. Microbiol. Biotechnol. 2020, 104, 527-543. [CrossRef]

15. Long, J.; Xu, Y.; Zhao, W.; Li, H.; Yang, S. Heterogeneous Catalytic Upgrading of Biofuranic Aldehydes to Alcohols. Front. Chem. 2019, 7, 529. [CrossRef]

16. Nilges, P.; Schröder, U. Electrochemistry for Biofuel Generation: Production of Furans by Electrocatalytic Hydrogenation of Furfurals. Energy Environ. Sci. 2013, 6, 2925. [CrossRef]

17. Gallezot, P. Conversion of Biomass to Selected Chemical Products. Chem. Soc. Rev. 2012, 41, 1538-1558. [CrossRef]

18. Scarlat, N.; Dallemand, J.-F.; Monforti-Ferrario, F.; Nita, V. The Role of Biomass and Bioenergy in a Future Bioeconomy: Policies and Facts. Environ. Dev. 2015, 15, 3-34. [CrossRef]

19. Takkellapati, S.; Li, T.; Gonzalez, M.A. An Overview of Biorefinery-Derived Platform Chemicals from a Cellulose and Hemicellulose Biorefinery. Clean Technol. Environ. Policy 2018, 20, 1615-1630. [CrossRef]

20. Kohli, K.; Prajapati, R.; Sharma, B. Bio-Based Chemicals from Renewable Biomass for Integrated Biorefineries. Energies 2019, 12, 233. [CrossRef]

21. Hou, Q.; Qi, X.; Zhen, M.; Qian, H.; Nie, Y.; Bai, C.; Zhang, S.; Bai, X.; Ju, M. Biorefinery Roadmap Based on Catalytic Production and Upgrading 5-Hydroxymethylfurfural. Green Chem. 2021, 23, 119-231. [CrossRef]

22. Li, S.; Ma, Q.; Zhong, W.; Zhao, X.; Wei, X.; Zhang, X.; Liu, Q.; Wang, C.; Ma, L.; Zhang, Q. One-Pot Hydrodeoxygenation of Bioderived Furans into Octane at Low Temperatures via an Octanediol Route. Green Chem. 2021, 23, 4741-4752. [CrossRef]

23. Dutta, S. Hydro(Deoxygenation) Reaction Network of Lignocellulosic Oxygenates. ChemSusChem 2020, 13, 2894-2915. [CrossRef] [PubMed]

24. Yan, L.; Zhang, Q.; Deng, W.; Zhang, Q.; Wang, Y. Catalytic valorization of biomass and bioplatforms to chemicals through deoxygenation. In Advances in Catalysis; Elsevier: Amherst, MA, USA, 2020; Volume 66, pp. 1-108, ISBN 978-0-12-820369-9.

25. De, S.; Saha, B.; Luque, R. Hydrodeoxygenation Processes: Advances on Catalytic Transformations of Biomass-Derived Platform Chemicals into Hydrocarbon Fuels. Bioresour. Technol. 2015, 178, 108-118. [CrossRef] [PubMed]

26. Gandarias, I.; Luis, P. Hydrotreating Catalytic Processes for Oxygen Removal in the Upgrading of Bio-Oils and Bio-Chemicals. In Liquid, Gaseous and Solid Biofuels_Conversion Techniques; Fang, Z., Ed.; InTech: London, UK, 2013; ISBN 978-953-51-1050-7.

27. Rogers, K.A.; Zheng, Y. Selective Deoxygenation of Biomass-Derived Bio-Oils within Hydrogen-Modest Environments: A Review and New Insights. ChemSusChem 2016, 9, 1750-1772. [CrossRef]

28. Kong, X.; Zhu, Y.; Fang, Z.; Kozinski, J.A.; Butler, I.S.; Xu, L.; Song, H.; Wei, X. Catalytic Conversion of 5-Hydroxymethylfurfural to Some Value-Added Derivatives. Green Chem. 2018, 20, 3657-3682. [CrossRef]

29. Kucherov, F.A.; Romashov, L.V.; Galkin, K.I.; Ananikov, V.P. Chemical Transformations of Biomass-Derived C6-Furanic Platform Chemicals for Sustainable Energy Research, Materials Science, and Synthetic Building Blocks. ACS Sustain. Chem. Eng. 2018, 6, 8064-8092. [CrossRef]

30. Thomas, J.M. The Societal Significance of Catalysis and the Growing Practical Importance of Single-Site Heterogeneous Catalysts. Proc. R. Soc. A 2012, 468, 1884-1903. [CrossRef] 
31. Huber, G.W.; Iborra, S.; Corma, A. Synthesis of Transportation Fuels from Biomass: Chemistry, Catalysts, and Engineering. Chem. Rev. 2006, 106, 4044-4098. [CrossRef]

32. Delidovich, I.; Palkovits, R. Catalytic versus Stoichiometric Reagents as a Key Concept for Green Chemistry. Green Chem. 2016, 18, 590-593. [CrossRef]

33. Cornils, B.; Herrmann, W.A. Concepts in Homogeneous Catalysis: The Industrial View. J. Catal. 2003, 216, 23-31. [CrossRef]

34. Jess, A.; Wasserscheid, P. Chemical Technology: From Principles to Products, 2nd ed.; Wiley: Weinheim, Germany, 2020; ISBN 978-3-527-34421-5.

35. Knowles, W.S.; Sabacky, M.J. Catalytic Asymmetric Hydrogenation Employing a Soluble, Optically Active, Rhodium Complex. Chem. Commun. 1968, 1445-1446. [CrossRef]

36. Knowles, W.S. Asymmetric Hydrogenations (Nobel Lecture). Angew. Chem. Int. Ed. 2002, 41, 1998-2007. [CrossRef]

37. Knowles, W.S.; Sabacky, M.J.; Vineyard, B.D. US Patent 4 005.127, 1977. US Patent 4 005.127, 1977.

38. Noyori, R. Asymmetric Catalysis: Science and Opportunities (Nobel Lecture). Angew. Chem. Int. Ed. 2002, 41, 2008-2022. [CrossRef]

39. Federsel, H.-J. Asymmetry on Large Scale: The Roadmap to Stereoselective Processes. Nat. Rev. Drug Discov. 2005, 4, 685-697. [CrossRef]

40. Pan, J.; Dang, N.-D.; Zheng, G.-W.; Cheng, B.; Ye, Q.; Xu, J.-H. Efficient Production of L-Menthol in a Two-Phase System with SDS Using an Immobilized Bacillus Subtilis Esterase. Bioresour. Bioprocess. 2014, 1, 12. [CrossRef]

41. Knowles, W.S.; Sabacky, M.J.; Vineyard, B.D.; Weinkauff, D.J. Asymmetric Hydrogenation with a Complex of Rhodium and a Chiral Bisphosphine. J. Am. Chem. Soc. 1975, 97, 2567-2568. [CrossRef]

42. Wolfson, A.; Vankelecom, I.F.J.; Geresh, S.; Jacobs, P.A. The Role of the Solvent in the Asymmetric Hydrogenation of $\beta$-Keto Esters with Ru-BINAP. J. Mol. Catal. A Chem. 2003, 198, 39-45. [CrossRef]

43. Kumobayashi, H.; Miura, T.; Sayo, N.; Saito, T.; Zhang, X. Recent Advances of BINAP Chemistry in the Industrial Aspects. Synlett 2001, 2001, 1055-1064. [CrossRef]

44. Clark, J.H. Green Chemistry for the Second Generation Biorefinery-Sustainable Chemical Manufacturing Based on Biomass. J. Chem. Technol. Biotechnol. 2007, 82, 603-609. [CrossRef]

45. Hu, L.; Lin, L.; Wu, Z.; Zhou, S.; Liu, S. Recent Advances in Catalytic Transformation of Biomass-Derived 5-Hydroxymethylfurfural into the Innovative Fuels and Chemicals. Renew. Sustain. Energy Rev. 2017, 74, 230-257. [CrossRef]

46. Shylesh, S.; Gokhale, A.A.; Ho, C.R.; Bell, A.T. Novel Strategies for the Production of Fuels, Lubricants, and Chemicals from Biomass. Acc. Chem. Res. 2017, 50, 2589-2597. [CrossRef]

47. Ruiz, J.; Jimenez-Sanchidrian, C. Heterogeneous Catalysis in the Meerwein-Ponndorf-Verley Reduction of Carbonyl Compounds. COC 2007, 11, 1113-1125. [CrossRef]

48. Meng, Q.; Zheng, H.; Zhu, Y.; Li, Y. Study on the Reaction Pathway in Decarbonylation of Biomass-Derived 5-Hydroxymethylfurfural over Pd-Based Catalyst. J. Mol. Catal. A Chem. 2016, 421, 76-82. [CrossRef]

49. Yuan, H.; Li, J.-P.; Su, F.; Yan, Z.; Kusema, B.T.; Streiff, S.; Huang, Y.; Pera-Titus, M.; Shi, F. Reductive Amination of Furanic Aldehydes in Aqueous Solution over Versatile $\mathrm{Ni}_{y} \mathrm{AlO}_{x}$ Catalysts. ACS Omega 2019, 4, 2510-2516. [CrossRef] [PubMed]

50. Merino, P.; Tejero, T.; Delso, J.I.; Matute, R. Furan Oxidations in Organic Synthesis: Recent Advances and Applications. COC 2007, 11, 1076-1091. [CrossRef]

51. da Silva, M.J.; Teixeira, M.G.; Natalino, R. Highly Selective Synthesis under Benign Reaction Conditions of Furfural Dialkyl Acetal Using $\mathrm{SnCl}_{2}$ as a Recyclable Catalyst. New J. Chem. 2019, 43, 8606-8612. [CrossRef]

52. Xu, M.; Richard, F.; Corbet, M.; Marion, P.; Clacens, J.-M. Upgrading of Furfural by Knoevenagel Condensation over Functionalized Carbonaceous Basic Catalysts. Catal. Commun. 2019, 130, 105777. [CrossRef]

53. Kumar, P.; Dutta, S.; Kumar, S.; Bahadur, V.; Van der Eycken, E.V.; Vimaleswaran, K.S.; Parmar, V.S.; Singh, B.K. Aldehydes: Magnificent Acyl Equivalents for Direct Acylation. Org. Biomol. Chem. 2020, 18, 7987-8033. [CrossRef]

54. Galkin, K.I.; Ananikov, V.P. The Increasing Value of Biomass: Moving From C6 Carbohydrates to Multifunctionalized Building Blocks via 5-(Hydroxymethyl)Furfural. ChemistryOpen 2020, 9, 1135-1148. [CrossRef]

55. Fernando, S.; Adhikari, S.; Chandrapal, C.; Murali, N. Biorefineries: Current Status, Challenges, and Future Direction. Energy Fuels 2006, 20, 1727-1737. [CrossRef]

56. Catoire, L.; Yahyaoui, M.; Osmont, A.; Gökalp, I.; Brothier, M.; Lorcet, H.; Guénadou, D. Thermochemistry of Compounds Formed during Fast Pyrolysis of Lignocellulosic Biomass. Energy Fuels 2008, 22, 4265-4273. [CrossRef]

57. Ruppert, A.M.; Weinberg, K.; Palkovits, R. Hydrogenolysis Goes Bio: From Carbohydrates and Sugar Alcohols to Platform Chemicals. Angew. Chem. Int. Ed. 2012, 51, 2564-2601. [CrossRef] [PubMed]

58. Chen, S.; Wojcieszak, R.; Dumeignil, F.; Marceau, E.; Royer, S. How Catalysts and Experimental Conditions Determine the Selective Hydroconversion of Furfural and 5-Hydroxymethylfurfural. Chem. Rev. 2018, 118, 11023-11117. [CrossRef]

59. Bhaumik, P.; Dhepe, P.L. Solid Acid Catalyzed Synthesis of Furans from Carbohydrates. Cataly. Rev. 2016, 58, 36-112. [CrossRef]

60. Zhang, Z.C. Chapter 3-Emerging Catalysis for 5-HMF Formation from Cellulosic Carbohydrates. In New and Future Developments in Catalysis; Elsevier: Amsterdam, The Netherlands, 2013; pp. 53-71, ISBN 978-0-444-53878-9.

61. Thoma, C.; Konnerth, J.; Sailer-Kronlachner, W.; Solt, P.; Rosenau, T.; Herwijnen, H.W.G. Current Situation of the Challenging Scale-Up Development of Hydroxymethylfurfural Production. ChemSusChem 2020, 13, 3544-3564. [CrossRef] [PubMed] 
62. Jing, Y.; Guo, Y.; Xia, Q.; Liu, X.; Wang, Y. Catalytic Production of Value-Added Chemicals and Liquid Fuels from Lignocellulosic Biomass. Chem 2019, 5, 2520-2546. [CrossRef]

63. Kunkes, E.L.; Simonetti, D.A.; West, R.M.; Serrano-Ruiz, J.C.; Gartner, C.A.; Dumesic, J.A. Catalytic Conversion of Biomass to Monofunctional Hydrocarbons and Targeted Liquid-Fuel Classes. Science 2008, 322, 417-421. [CrossRef]

64. Rosatella, A.A.; Simeonov, S.P.; Frade, R.F.M.; Afonso, C.A.M. 5-Hydroxymethylfurfural (HMF) as a Building Block Platform: Biological Properties, Synthesis and Synthetic Applications. Green Chem. 2011, 13, 754. [CrossRef]

65. Scapin, E.; Rambo, M.K.D.; Viana, G.C.C.; Marasca, N.; Lacerda, G.E.; Rambo, M.C.D.; Fernandes, R.d.M.N. Sustainable Production of Furfural and 5-Hidroximetilfurfural from Rice Husks and Soybean Peel by Using Ionic Liquid. Food Sci. Technol. 2020, 40, 83-87. [CrossRef]

66. Kläusli, T. AVA Biochem: Commercialising Renewable Platform Chemical 5-HMF. Green Process. Synth. 2014, 3, 235-236. [CrossRef]

67. Yan, K.; Wu, G.; Lafleur, T.; Jarvis, C. Production, Properties and Catalytic Hydrogenation of Furfural to Fuel Additives and Value-Added Chemicals. Renew. Sustain. Energy Rev. 2014, 38, 663-676. [CrossRef]

68. Simeonov, S.P.; Lazarova, H.I.; Marinova, M.K.; Popova, M.D. Achmatowicz Rearrangement Enables Hydrogenolysis-Free Gas-Phase Synthesis of Pentane-1,2,5-Triol from Furfuryl Alcohol. Green Chem. 2019, 21, 5657-5664. [CrossRef]

69. Zhu, J.; Yin, G. Catalytic Transformation of the Furfural Platform into Bifunctionalized Monomers for Polymer Synthesis. ACS Catal. 2021, 11, 10058-10083. [CrossRef]

70. Carniti, P.; Gervasini, A.; Marzo, M. Absence of Expected Side-Reactions in the Dehydration Reaction of Fructose to HMF in Water over Niobic Acid Catalyst. Catal. Commun. 2011, 12, 1122-1126. [CrossRef]

71. Song, J.; Fan, H.; Ma, J.; Han, B. Conversion of Glucose and Cellulose into Value-Added Products in Water and Ionic Liquids. Green Chem. 2013, 15, 2619. [CrossRef]

72. Seri, K.; Inoue, Y.; Ishida, H. Catalytic Activity of Lanthanide(III) Ions for the Dehydration of Hexose to 5-Hydroxymethyl-2Furaldehyde in Water. BCSJ 2001, 74, 1145-1150. [CrossRef]

73. Hu, L.; Sun, Y.; Lin, L. Efficient Conversion of Glucose into 5-Hydroxymethylfurfural by Chromium(III) Chloride in Inexpensive Ionic Liquid. Ind. Eng. Chem. Res. 2012, 51, 1099-1104. [CrossRef]

74. Li, C.; Zhang, Z.; Zhao, Z.K. Direct Conversion of Glucose and Cellulose to 5-Hydroxymethylfurfural in Ionic Liquid under Microwave Irradiation. Tetrahedron Lett. 2009, 50, 5403-5405. [CrossRef]

75. Hu, L.; Wu, Z.; Jiang, Y.; Wang, X.; He, A.; Song, J.; Xu, J.; Zhou, S.; Zhao, Y.; Xu, J. Recent Advances in Catalytic and Autocatalytic Production of Biomass-Derived 5-Hydroxymethylfurfural. Renew. Sustain. Energy Rev. 2020, 134, 110317. [CrossRef]

76. Zhao, H.; Holladay, J.E.; Brown, H.; Zhang, Z.C. Metal Chlorides in Ionic Liquid Solvents Convert Sugars to 5-Hydroxymethylfurfural. Science 2007, 316, 1597-1600. [CrossRef]

77. Dunn, E.F.; Liu, D.; Chen, E.Y.-X. Role of N-Heterocyclic Carbenes in Glucose Conversion into HMF by Cr Catalysts in Ionic Liquids. Appl. Catal. A Gen. 2013, 460-461,1-7. [CrossRef]

78. Enslow, K.R.; Bell, A.T. SnCl 4 -Catalyzed Isomerization/Dehydration of Xylose and Glucose to Furanics in Water. Catal. Sci. Technol. 2015, 5, 2839-2847. [CrossRef]

79. Liu, F.; Audemar, M.; De Oliveira Vigier, K.; Cartigny, D.; Clacens, J.-M.; Costa Gomes, M.F.; Pádua, A.A.H.; De Campo, F.; Jérôme, F. Selectivity Enhancement in the Aqueous Acid-Catalyzed Conversion of Glucose to 5-Hydroxymethylfurfural Induced by Choline Chloride. Green Chem. 2013, 15, 3205. [CrossRef]

80. Yan, L.; Ma, R.; Wei, H.; Li, L.; Zou, B.; Xu, Y. Ruthenium Trichloride Catalyzed Conversion of Cellulose into 5Hydroxymethylfurfural in Biphasic System. Bioresour. Technol. 2019, 279, 84-91. [CrossRef] [PubMed]

81. Wei, Z.; Li, Y.; Thushara, D.; Liu, Y.; Ren, Q. Novel Dehydration of Carbohydrates to 5-Hydroxymethylfurfural Catalyzed by Ir and Au Chlorides in Ionic Liquids. J. Taiwan Inst. Chem. Eng. 2011, 42, 363-370. [CrossRef]

82. Liu, B.; Zhang, Z.; Zhao, Z.K. Microwave-Assisted Catalytic Conversion of Cellulose into 5-Hydroxymethylfurfural in Ionic Liquids. Chem. Eng. J. 2013, 215-216, 517-521. [CrossRef]

83. Dutta, S.; De, S.; Alam, M.I.; Abu-Omar, M.M.; Saha, B. Direct Conversion of Cellulose and Lignocellulosic Biomass into Chemicals and Biofuel with Metal Chloride Catalysts. J. Catal. 2012, 288, 8-15. [CrossRef]

84. Zhang, Z.; Liu, B.; Zhao, Z.K. Catalytic Conversion of Carbohydrates into 5-Hydroxymethylfurfural by Hafnium(IV) Chloride in Ionic Liquids. Starch Stärke 2012, 64, 770-775. [CrossRef]

85. Mittal, N.; Nisola, G.M.; Chung, W.-J. Facile Catalytic Dehydration of Fructose to 5-Hydroxymethylfurfural by Niobium Pentachloride. Tetrahedron Lett. 2012, 53, 3149-3155. [CrossRef]

86. Beckerle, K.; Okuda, J. Conversion of Glucose and Cellobiose into 5-Hydroxymethylfurfural (HMF) by Rare Earth Metal Salts in N,N'-Dimethylacetamide (DMA). J. Mol. Catal. A Chem. 2012, 356, 158-164. [CrossRef]

87. Zhang, Y.; Du, H.; Qian, X.; Chen, E.Y.-X. Ionic Liquid-Water Mixtures: Enhanced $K_{\mathrm{w}}$ for Efficient Cellulosic Biomass Conversion. Energy Fuels 2010, 24, 2410-2417. [CrossRef]

88. Wrigstedt, P.; Keskiväli, J.; Leskelä, M.; Repo, T. The Role of Salts and Brønsted Acids in Lewis Acid-Catalyzed Aqueous-Phase Glucose Dehydration to 5-Hydroxymethylfurfural. ChemCatChem 2015, 7, 501-507. [CrossRef]

89. Yadav, K.K.; Ahmad, S.; Chauhan, S.M.S. Elucidating the Role of Cobalt Phthalocyanine in the Dehydration of Carbohydrates in Ionic Liquids. J. Mol. Catal. A Chem. 2014, 394, 170-176. [CrossRef] 
90. Wang, F.; Shi, A.-W.; Qin, X.-X.; Liu, C.-L.; Dong, W.-S. Dehydration of Fructose to 5-Hydroxymethylfurfural by Rare Earth Metal Trifluoromethanesulfonates in Organic Solvents. Carbohydr. Res. 2011, 346, 982-985. [CrossRef] [PubMed]

91. Choudhary, V.; Sandler, S.I.; Vlachos, D.G. Conversion of Xylose to Furfural Using Lewis and Brønsted Acid Catalysts in Aqueous Media. ACS Catal. 2012, 2, 2022-2028. [CrossRef]

92. Marcotullio, G.; De Jong, W. Chloride Ions Enhance Furfural Formation from D-Xylose in Dilute Aqueous Acidic Solutions. Green Chem. 2010, 12, 1739. [CrossRef]

93. Danon, B.; Marcotullio, G.; de Jong, W. Mechanistic and Kinetic Aspects of Pentose Dehydration towards Furfural in Aqueous Media Employing Homogeneous Catalysis. Green Chem. 2014, 16, 39-54. [CrossRef]

94. Liu, C.; Wyman, C.E. The Enhancement of Xylose Monomer and Xylotriose Degradation by Inorganic Salts in Aqueous Solutions at $180{ }^{\circ}$ C. Carbohydr. Res. 2006, 341, 2550-2556. [CrossRef]

95. Hart, D. Hydrogen, End Uses and Economics. In Encyclopedia of Energy; Elsevier: London, UK, 2004; pp. 231-239, ISBN 978-0-12-176480-7.

96. Nakagawa, Y.; Tamura, M.; Tomishige, K. Catalytic Reduction of Biomass-Derived Furanic Compounds with Hydrogen. ACS Catal. 2013, 3, 2655-2668. [CrossRef]

97. Ralphs, K.; McCourt, É;; Ormandy, C.; Carneiro de Souza, T.A.; Nockemann, P.; Jacquemin, J.; Manyar, H.G. Highly Selective Reduction of $\alpha, \beta$-Unsaturated Aldehydes and Ketones under Ambient Conditions Using Tetraalkylphosphonium-based Ionic Liquids. ChemistrySelect 2018, 3, 11706-11711. [CrossRef]

98. Zhang, J.; Wang, T.; Tang, X.; Peng, L.; Wei, J.; Lin, L. Methods in the synthesis and conversion of 2,5-Bis-(hydroxylmethyl)furan from bio-derived 5-hydroxymethylfurfural and its great potential in polymerization. BioResources 2018, 13, 7137-7154. [CrossRef]

99. Wang, T.; Zhang, J.; Xie, W.; Tang, Y.; Guo, D.; Ni, Y. Catalytic Transfer Hydrogenation of Biobased HMF to 2,5-Bis(Hydroxymethyl)Furan over $\mathrm{Ru} / \mathrm{Co}_{3} \mathrm{O}_{4}$. Catalysts 2017, 7, 92. [CrossRef]

100. Nakagawa, Y.; Tamura, M.; Tomishige, K. Supported Metal Catalysts for Total Hydrogenation of Furfural and 5Hydroxymethylfurfural. J. Jpn. Pet. Inst. 2017, 60, 1-9. [CrossRef]

101. Corma, A.; Iborra, S.; Velty, A. Chemical Routes for the Transformation of Biomass into Chemicals. Chem. Rev. 2007, 107, 2411-2502. [CrossRef]

102. Koley, P.; Rao, B.S.; Sabri, Y.M.; Bhargava, S.K.; Tardio, J.; Lingaiah, N. Selective Conversion of Furfural into Tetrahydrofurfuryl Alcohol Using a Heteropoly Acid-Based Material as a Hydrogenation Catalyst. Sustain. Energy Fuels 2020, 4, 4768-4779. [CrossRef]

103. Yang, F.; Fu, J.; Mo, J.; Lu, X. Synergy of Lewis and Brønsted Acids on Catalytic Hydrothermal Decomposition of Hexose to Levulinic Acid. Energy Fuels 2013, 27, 6973-6978. [CrossRef]

104. Jansen, E.; Jongbloed, L.S.; Tromp, D.S.; Lutz, M.; de Bruin, B.; Elsevier, C.J. Ligand Effects on the Hydrogenation of BiomassInspired Substrates with Bifunctional Ru, Ir, and Rh Complexes. ChemSusChem 2013, 6, 1737-1744. [CrossRef]

105. Cadu, A.; Sekine, K.; Mormul, J.; Ohlmann, D.M.; Schaub, T.; Hashmi, A.S.K. Homogeneous Catalysed Hydrogenation of HMF. Green Chem. 2018, 20, 3386-3393. [CrossRef]

106. Pasini, T.; Solinas, G.; Zanotti, V.; Albonetti, S.; Cavani, F.; Vaccari, A.; Mazzanti, A.; Ranieri, S.; Mazzoni, R. Substrate and Product Role in the Shvo's Catalyzed Selective Hydrogenation of the Platform Bio-Based Chemical 5-Hydroxymethylfurfural. Dalton Trans. 2014, 43, 10224-10234. [CrossRef] [PubMed]

107. Padilla, R.; Koranchalil, S.; Nielsen, M. Efficient and Selective Catalytic Hydrogenation of Furanic Aldehydes Using Well Defined $\mathrm{Ru}$ and Ir Pincer Complexes. Green Chem. 2020, 22, 6767-6772. [CrossRef]

108. Dach, R.; Song, J.J.; Roschangar, F.; Samstag, W.; Senanayake, C.H. The Eight Criteria Defining a Good Chemical Manufacturing Process. Org. Process. Res. Dev. 2012, 16, 1697-1706. [CrossRef]

109. Elangovan, S.; Topf, C.; Fischer, S.; Jiao, H.; Spannenberg, A.; Baumann, W.; Ludwig, R.; Junge, K.; Beller, M. Selective Catalytic Hydrogenations of Nitriles, Ketones, and Aldehydes by Well-Defined Manganese Pincer Complexes. J. Am. Chem. Soc. 2016, 138, 8809-8814. [CrossRef] [PubMed]

110. Falco, G.; Guigo, N.; Vincent, L.; Sbirrazzuoli, N. FA Polymerization Disruption by Protic Polar Solvents. Polymers 2018, 10, 529. [CrossRef]

111. Huang, F.; Li, W.; Lu, Q.; Zhu, X. Homogeneous Catalytic Hydrogenation of Bio-Oil and Related Model Aldehydes with RuCl2(PPh3)3. Chem. Eng. Technol. 2010, 33, 2082-2088. [CrossRef]

112. Bhor, M.D.; Panda, A.G.; Nandurkar, N.S.; Bhanage, B.M. Synthesis of Alkyl Iodides/Nitriles from Carbonyl Compounds Using Novel Ruthenium Tris(2,2,6,6-Tetramethyl-3,5-Heptanedionate) as Catalyst. Tetrahedron Lett. 2008, 49, 6475-6479. [CrossRef]

113. Strassberger, Z.; Mooijman, M.; Ruijter, E.; Alberts, A.H.; de Graaff, C.; Orru, R.V.A.; Rothenberg, G. A Facile Route to RutheniumCarbene Complexes and Their Application in Furfural Hydrogenation. Appl. Organomet. Chem. 2009, 24, 142-146. [CrossRef]

114. Strassberger, Z.; Mooijman, M.; Ruijter, E.; Alberts, A.H.; Maldonado, A.G.; Orru, R.V.A.; Rothenberg, G. Finding Furfural Hydrogenation Catalysts via Predictive Modelling. Adv. Synth. Catal. 2010, 352, 2201-2210. [CrossRef]

115. Tukacs, J.M.; Bohus, M.; Dibó, G.; Mika, L.T. Ruthenium-Catalyzed Solvent-Free Conversion of Furfural to Furfuryl Alcohol. RSC Adv. 2017, 7, 3331-3335. [CrossRef]

116. Gowda, A.S.; Parkin, S.; Ladipo, F.T. Hydrogenation and Hydrogenolysis of Furfural and Furfuryl Alcohol Catalyzed by Ruthenium(II) Bis(Diimine) Complexes: Ru(II)-Catalyzed Hydrogenation and Hydrogenolysis of Furfural. Appl. Organomet. Chem. 2012, 26, 86-93. [CrossRef] 
117. Wu, W.-P.; Xu, Y.-J.; Chang, S.-W.; Deng, J.; Fu, Y. PH-Regulated Aqueous Catalytic Hydrogenation of Biomass Carbohydrate Derivatives by Using Semisandwich Iridium Complexes. ChemCatChem 2016, 8, 3375-3380. [CrossRef]

118. Garhwal, S.; Maji, B.; Semwal, S.; Choudhury, J. Ambient-Pressure and Base-Free Aldehyde Hydrogenation Catalyst Supported by a Bifunctional Abnormal NHC Ligand. Organometallics 2018, 37, 4720-4725. [CrossRef]

119. Christie, F.; Zanotti-Gerosa, A.; Grainger, D. Hydrogenation and Reductive Amination of Aldehydes Using Triphos Ruthenium Catalysts. ChemCatChem 2018, 10, 1012-1018. [CrossRef]

120. Moyo, P.S.; Matsinha, L.C.; Makhubela, B.C.E. Pd(II) and Pt(II) Catalysed Selective Synthesis of Furfuryl Alcohol: Solvent Effects and Insights into the Mechanism. J. Organomet. Chem. 2020, 922, 121362. [CrossRef]

121. Valdebenito, G.; Parra-Melipán, S.; López, V.; Aranda, B.; García, E.; Vega, A.; Negrete-Vergara, C.; Moya, S.A.; Aguirre, P. Selective Hydrogenation of Furfural to Furfuryl Alcohol Catalysed by Ruthenium Complexes Containing Phosphorus-nitrogen Ligands. Appl. Organomet. Chem. 2021, 35, e6382. [CrossRef]

122. Bullock, R.M. Abundant Metals Give Precious Hydrogenation Performance. Science 2013, 342, 1054-1055. [CrossRef]

123. Wienhöfer, G.; Westerhaus, F.A.; Junge, K.; Ludwig, R.; Beller, M. A Molecularly Defined Iron-Catalyst for the Selective Hydrogenation of $\alpha, \beta$-Unsaturated Aldehydes. Chem. Eur. J. 2013, 19, 7701-7707. [CrossRef]

124. Gorgas, N.; Stöger, B.; Veiros, L.F.; Kirchner, K. Highly Efficient and Selective Hydrogenation of Aldehydes: A Well-Defined Fe(II) Catalyst Exhibits Noble-Metal Activity. ACS Catal. 2016, 6, 2664-2672. [CrossRef] [PubMed]

125. Weber, S.; Brünig, J.; Zeindlhofer, V.; Schröder, C.; Stöger, B.; Limbeck, A.; Kirchner, K.; Bica, K. Selective Hydrogenation of Aldehydes Using a Well-Defined Fe(II) PNP Pincer Complex in Biphasic Medium. ChemCatChem 2018, 10, 4386-4394. [CrossRef] [PubMed]

126. Csendes, Z.; Brünig, J.; Yigit, N.; Rupprechter, G.; Bica-Schröder, K.; Hoffmann, H.; Kirchner, K. Influence of the Ionic Liquid on the Activity of a Supported Ionic Liquid Phase Fe II Pincer Catalyst for the Hydrogenation of Aldehydes: Influence of the Ionic Liquid on the Activity of a Supported Ionic Liquid Phase Fe II Pincer Catalyst for the Hydrogenation of Aldehydes. Eur. J. Inorg. Chem. 2019, 3503-3510. [CrossRef]

127. Mukherjee, A.; Milstein, D. Homogeneous Catalysis by Cobalt and Manganese Pincer Complexes. ACS Catal. 2018, 8, 11435-11469. [CrossRef]

128. Yang, W.; Chernyshov, I.Y.; van Schendel, R.K.A.; Weber, M.; Müller, C.; Filonenko, G.A.; Pidko, E.A. Robust and Efficient Hydrogenation of Carbonyl Compounds Catalysed by Mixed Donor Mn(I) Pincer Complexes. Nat. Commun 2021, 12, 12. [CrossRef]

129. Glatz, M.; Stöger, B.; Himmelbauer, D.; Veiros, L.F.; Kirchner, K. Chemoselective Hydrogenation of Aldehydes under Mild, Base-Free Conditions: Manganese Outperforms Rhenium. ACS Catal. 2018, 8, 4009-4016. [CrossRef] [PubMed]

130. Klomp, D.; Hanefeld, U.; Peters, J.A. Transfer Hydrogenation Including the Meerwein-Ponndorf-Verley Reduction. In The Handbook of Homogeneous Hydrogenation; de Vries, J.G., Elsevier, C.J., Eds.; Wiley: Weinheim, Germany, 2006; pp. 585-630, ISBN 978-3-527-61938-2.

131. Gladiali, S.; Taras, R. Reduction of Carbonyl Compounds by Hydrogen Transfer. In Modern Reduction Methods; Andersson, P.G., Munslow, I.J., Eds.; Wiley: Weinheim, Germany, 2008; pp. 135-157, ISBN 978-3-527-62211-5.

132. Gliński, M.; Ulkowska, U. Reactivity of Alcohols in Chemoselective Transfer Hydrogenation of Acrolein over Magnesium Oxide as the Catalyst. Catal. Lett. 2011, 141, 293-299. [CrossRef]

133. Scholz, D.; Aellig, C.; Hermans, I. Catalytic Transfer Hydrogenation/Hydrogenolysis for Reductive Upgrading of Furfural and 5-(Hydroxymethyl)Furfural. ChemSusChem 2014, 7, 268-275. [CrossRef]

134. Baldino, S.; Facchetti, S.; Nedden, H.G.; Zanotti-Gerosa, A.; Baratta, W. Chemoselective Transfer Hydrogenation of Aldehydes with $\mathrm{HCOONH}_{4}$ Catalyzed by $\mathrm{RuCl}\left(\mathrm{CNN}^{\mathrm{Ph}}\right)(\mathrm{PP})$ Pincer Complexes. ChemCatChem 2016, 8, 3195-3198. [CrossRef]

135. Townsend, T.M.; Kirby, C.; Ruff, A.; O'Connor, A.R. Transfer Hydrogenation of Aromatic and Linear Aldehydes Catalyzed Using Cp*Ir(Pyridinesulfonamide)Cl Complexes under Base-Free Conditions. J. Organomet. Chem. 2017, 843, 7-13. [CrossRef]

136. Aboo, A.H.; Bennett, E.L.; Deeprose, M.; Robertson, C.M.; Iggo, J.A.; Xiao, J. Methanol as Hydrogen Source: Transfer Hydrogenation of Aromatic Aldehydes with a Rhodacycle. Chem. Commun. 2018, 54, 11805-11808. [CrossRef]

137. Farrar-Tobar, R.A.; Wei, Z.; Jiao, H.; Hinze, S.; de Vries, J.G. Selective Base-Free Transfer Hydrogenation of $\alpha, \beta-U n s a t u r a t e d$ Carbonyl Compounds Using $i \mathrm{PrOH}$ or EtOH as Hydrogen Source. Chem. Eur. J. 2018, 24, 2725-2734. [CrossRef] [PubMed]

138. Ghosh, R.; Jana, N.C.; Panda, S.; Bagh, B. Transfer Hydrogenation of Aldehydes and Ketones in Air with Methanol and Ethanol by an Air-Stable Ruthenium-Triazole Complex. ACS Sustain. Chem. Eng. 2021, 9, 4903-4914. [CrossRef]

139. Oklu, N.K.; Makhubela, B.C.E. Chemoselective and Efficient Catalytic Hydrogenation of Furfural by Iridium and Ruthenium Half-Sandwich Complexes. New J. Chem. 2020, 44, 9382-9390. [CrossRef]

140. Gorgas, N.; Ilic, A.; Kirchner, K. Chemoselective Transfer Hydrogenation of Aldehydes in Aqueous Media Catalyzed by a Well-Defined Iron(II) Hydride Complex. Monatsh. Chem. 2019, 150, 121-126. [CrossRef]

141. Paul, A.; Shipman, M.A.; Onabule, D.Y.; Sproules, S.; Symes, M.D. Selective Aldehyde Reductions in Neutral Water Catalysed by Encapsulation in a Supramolecular Cage. Chem. Sci. 2021, 12, 5082-5090. [CrossRef]

142. Stadler, B.M.; Puylaert, P.; Diekamp, J.; van Heck, R.; Fan, Y.; Spannenberg, A.; Hinze, S.; de Vries, J.G. Inexpensive Ruthenium NNS-Complexes as Efficient Ester Hydrogenation Catalysts with High C $=\mathrm{O}$ vs. $\mathrm{C}=\mathrm{C}$ Selectivities. Adv. Synth. Catal. 2018, 360, 1151-1158. [CrossRef] 
143. Junge, K.; Wendt, B.; Jiao, H.; Beller, M. Iridium-Catalyzed Hydrogenation of Carboxylic Acid Esters. ChemCatChem 2014, 6, 2810-2814. [CrossRef]

144. Farrar-Tobar, R.A.; Wozniak, B.; Savini, A.; Hinze, S.; Tin, S.; de Vries, J.G. Base-Free Iron Catalyzed Transfer Hydrogenation of Esters Using EtOH as Hydrogen Source. Angew. Chem. Int. Ed. 2019, 58, 1129-1133. [CrossRef]

145. Elangovan, S.; Garbe, M.; Jiao, H.; Spannenberg, A.; Junge, K.; Beller, M. Hydrogenation of Esters to Alcohols Catalyzed by Defined Manganese Pincer Complexes. Angew. Chem. Int. Ed. 2016, 55, 15364-15368. [CrossRef]

146. Widegren, M.B.; Harkness, G.J.; Slawin, A.M.Z.; Cordes, D.B.; Clarke, M.L. A Highly Active Manganese Catalyst for Enantioselective Ketone and Ester Hydrogenation. Angew. Chem. Int. Ed. 2017, 56, 5825-5828. [CrossRef] [PubMed]

147. Zhang, L.; Tang, Y.; Han, Z.; Ding, K. Lutidine-Based Chiral Pincer Manganese Catalysts for Enantioselective Hydrogenation of Ketones. Angew. Chem. Int. Ed. 2019, 58, 4973-4977. [CrossRef] [PubMed]

148. Shono, T.; Matsumura, Y.; Hamaguchi, H. Easy Synthesis of 2-Hydroxy-3-Methylcyclopent-2-Enone. J. Chem. Soc. Chem. Commun. 1977, 712-713. [CrossRef]

149. Gupta, K.; Tyagi, D.; Dwivedi, A.D.; Mobin, S.M.; Singh, S.K. Catalytic Transformation of Bio-Derived Furans to Valuable Ketoacids and Diketones by Water-Soluble Ruthenium Catalysts. Green Chem. 2015, 17, 4618-4627. [CrossRef]

150. Xu, Z.; Yan, P.; Xu, W.; Liu, X.; Xia, Z.; Chung, B.; Jia, S.; Zhang, Z.C. Hydrogenation/Hydrolytic Ring Opening of 5-HMF by Cp*-Iridium(III) Half-Sandwich Complexes for Bioketones Synthesis. ACS Catal. 2015, 5, 788-792. [CrossRef]

151. Xu, Z.; Yan, P.; Li, H.; Liu, K.; Liu, X.; Jia, S.; Zhang, Z.C. Active Cp*Iridium(III) Complex with Ortho -Hydroxyl Group Functionalized Bipyridine Ligand Containing an Electron-Donating Group for the Production of Diketone from 5-HMF. ACS Catal. 2016, 6, 3784-3788. [CrossRef]

152. Wozniak, B.; Spannenberg, A.; Li, Y.; Hinze, S.; de Vries, J.G. Cyclopentanone Derivatives from 5-Hydroxymethylfurfural via 1-Hydroxyhexane-2,5-Dione as Intermediate. ChemSusChem 2018, 11, 356-359. [CrossRef] [PubMed]

153. Hill, J.; Nelson, E.; Tilman, D.; Polasky, S.; Tiffany, D. Environmental, Economic, and Energetic Costs and Benefits of Biodiesel and Ethanol Biofuels. Proc. Natl. Acad. Sci. USA 2006, 103, 11206-11210. [CrossRef] [PubMed]

154. Cai, C.M.; Zhang, T.; Kumar, R.; Wyman, C.E. Integrated Furfural Production as a Renewable Fuel and Chemical Platform from Lignocellulosic Biomass: Furfural Production from Lignocellulosic Biomass. J. Chem. Technol. Biotechnol. 2014, 89, 2-10. [CrossRef]

155. Vinod, N.; Dutta, S. Energy Densification of Biomass-Derived Furfurals to Furanic Biofuels by Catalytic Hydrogenation and Hydrodeoxygenation Reactions. Sustain. Chem. 2021, 2, 521-549. [CrossRef]

156. Makhubela, B.C.E.; Darkwa, J. The Role of Noble Metal Catalysts in Conversion of Biomass and Bio-Derived Intermediates to Fuels and Chemicals. Johns. Matthey Technol. Rev. 2018, 62, 4-31. [CrossRef]

157. Tian, G.; Daniel, R.; Li, H.; Xu, H.; Shuai, S.; Richards, P. Laminar Burning Velocities of 2,5-Dimethylfuran Compared with Ethanol and Gasoline. Energy Fuels 2010, 24, 3898-3905. [CrossRef]

158. Nagpure, A.S.; Lucas, N.; Chilukuri, S.V. Efficient Preparation of Liquid Fuel 2,5-Dimethylfuran from Biomass-Derived 5Hydroxymethylfurfural over Ru-NaY Catalyst. ACS Sustain. Chem. Eng. 2015, 3, 2909-2916. [CrossRef]

159. Román-Leshkov, Y.; Barrett, C.J.; Liu, Z.Y.; Dumesic, J.A. Production of Dimethylfuran for Liquid Fuels from Biomass-Derived Carbohydrates. Nature 2007, 447, 982-985. [CrossRef]

160. Sezer, İ. Thermodynamic, Performance and Emission Investigation of a Diesel Engine Running on Dimethyl Ether and Diethyl Ether. Int. J. Therm. Sci. 2011, 50, 1594-1603. [CrossRef]

161. Liu, X.; Wang, R. Upgrading of Carbohydrates to the Biofuel Candidate 5-Ethoxymethylfurfural (EMF). Int. J. Chem. Eng. 2018, 2018, 1-10. [CrossRef]

162. Chen, B.; Yan, G.; Chen, G.; Feng, Y.; Zeng, X.; Sun, Y.; Tang, X.; Lei, T.; Lin, L. Recent Progress in the Development of Advanced Biofuel 5-Ethoxymethylfurfural. BMC Energy 2020, 2, 2. [CrossRef]

163. Liu, J.; Tang, Y.; Wu, K.; Bi, C.; Cui, Q. Conversion of Fructose into 5-Hydroxymethylfurfural (HMF) and Its Derivatives Promoted by Inorganic Salt in Alcohol. Carbohydr. Res. 2012, 350, 20-24. [CrossRef]

164. Zhou, X.; Zhang, Z.; Liu, B.; Zhou, Q.; Wang, S.; Deng, K. Catalytic Conversion of Fructose into Furans Using FeCl3 as Catalyst. J. Ind. Eng. Chem. 2014, 20, 644-649. [CrossRef]

165. Lee, R.; Vanderveen, J.R.; Champagnffe, P.; Jessop, P.G. $\mathrm{CO}_{2}$-Catalysed Aldol Condensation of 5-Hydroxymethylfurfural and Acetone to a Jet Fuel Precursor. Green Chem. 2016, 18, 5118-5121. [CrossRef]

166. Si, Z.; Zhang, X.; Wang, C.; Ma, L.; Dong, R. An Overview on Catalytic Hydrodeoxygenation of Pyrolysis Oil and Its Model Compounds. Catalysts 2017, 7, 169. [CrossRef]

167. Schlaf, M. Homogeneous Catalysts for the Hydrodeoxygenation of Biomass-Derived Carbohydrate Feedstocks. In Reaction Pathways and Mechanisms in Thermocatalytic Biomass Conversion II; Schlaf, M., Zhang, Z.C., Eds.; Green Chemistry and Sustainable Technology; Springer: Singapore, 2016; pp. 13-38, ISBN 978-981-287-768-0.

168. Dedsuksophon, W.; Champreda, V.; Laosiripojana, N. Study of Liquid Alkanes Production from Biomass-Derived Carbohydrates by Aldol-Condensation and Hydrogenation Processes. EJ 2010, 14, 1-10. [CrossRef]

169. Sullivan, R.J.; Latifi, E.; Chung, B.K.-M.; Soldatov, D.V.; Schlaf, M. Hydrodeoxygenation of 2,5-Hexanedione and 2,5Dimethylfuran by Water-, Air-, and Acid-Stable Homogeneous Ruthenium and Iridium Catalysts. ACS Catal. 2014, 4, 4116-4128. [CrossRef]

170. Yang, W.; Grochowski, M.R.; Sen, A. Selective Reduction of Biomass by Hydriodic Acid and Its In Situ Regeneration from Iodine by Metal/Hydrogen. ChemSusChem 2012, 5, 1218-1222. [CrossRef] 
171. Mishra, D.K.; Cho, J.K.; Kim, Y.J. Facile Production of 2,5-Diformylfuran from Base-Free Oxidation of 5-Hydroxymethyl Furfural over Manganese-Cobalt Spinels Supported Ruthenium Nanoparticles. J. Ind. Eng. Chem. 2018, 60, 513-519. [CrossRef]

172. Wang, F.; Yuan, Z.; Liu, B.; Chen, S.; Zhang, Z. Catalytic Oxidation of Biomass Derived 5-Hydroxymethylfurfural (HMF) over Ru III -Incorporated Zirconium Phosphate Catalyst. J. Ind. Eng. Chem. 2016, 38, 181-185. [CrossRef]

173. Saravanamurugan, S.; Pandey, A.; Sangwan, R.S. Biomass-Derived HMF Oxidation with Various Oxidants. In Biofuels; Agarwal, A.K., Agarwal, R.A., Gupta, T., Gurjar, B.R., Eds.; Green Energy and Technology; Springer: Singapore, 2017; pp. 51-67, ISBN 978-981-10-3790-0.

174. Navarro, O.C.; Canós, A.C.; Chornet, S.I. Chemicals from Biomass: Aerobic Oxidation of 5-Hydroxymethyl-2-Furaldehyde into Diformylfurane Catalyzed by Immobilized Vanadyl-Pyridine Complexes on Polymeric and Organofunctionalized Mesoporous Supports. Top. Catal 2009, 52, 304-314. [CrossRef]

175. Jia, X.; Ma, J.; Wang, M.; Du, Z.; Lu, F.; Wang, F.; Xu, J. Promoted Role of $\mathrm{Cu}\left(\mathrm{NO}_{3}\right)_{2}$ on Aerobic Oxidation of 5Hydroxymethylfurfural to 2,5-Diformylfuran over $\mathrm{VOSO}_{4}$. Appl. Catal. A Gen. 2014, 482, 231-236. [CrossRef]

176. Ma, J.; Du, Z.; Xu, J.; Chu, Q.; Pang, Y. Efficient Aerobic Oxidation of 5-Hydroxymethylfurfural to 2,5-Diformylfuran, and Synthesis of a Fluorescent Material. ChemSusChem 2011, 4, 51-54. [CrossRef]

177. Dai, J. Synthesis of 2,5-Diformylfuran from Renewable Carbohydrates and Its Applications: A Review. Green Energy Environ. 2021, 6, 22-32. [CrossRef]

178. Dessbesell, L.; Souzanchi, S.; Venkateswara Rao, K.T.; Carrillo, A.A.; Bekker, D.; Hall, K.A.; Lawrence, K.M.; Tait, C.L.J.; Xu, C. (Charles) Production of 2,5-furandicarboxylic Acid (FDCA) from Starch, Glucose, or High-fructose Corn Syrup: Techno-economic Analysis. Biofuels Bioprod. Bioref. 2019, 13, 1234-1245. [CrossRef]

179. Cong, H.; Yuan, H.; Tao, Z.; Bao, H.; Zhang, Z.; Jiang, Y.; Huang, D.; Liu, H.; Wang, T. Recent Advances in Catalytic Conversion of Biomass to 2,5-Furandicarboxylic Acid. Catalysts 2021, 11, 1113. [CrossRef]

180. Zhang, Z.; Deng, K. Recent Advances in the Catalytic Synthesis of 2,5-Furandicarboxylic Acid and Its Derivatives. ACS Catal. 2015, 5, 6529-6544. [CrossRef]

181. Meraldo, A. Introduction to Bio-based Polymers. In Multilayer Flexible Packaging, 2nd ed.; Wagner, J.R., Ed.; Academic Press: New York, NY, USA, 2016; pp. 47-52. [CrossRef]

182. Verdeguer, P.; Merat, N.; Gaset, A. Oxydation Catalytique Du HMF En Acide 2,5-Furane Dicarboxylique. J. Mol. Catal. 1993, 85, 327-344. [CrossRef]

183. Hong, M.; Min, J.; Wu, S.; Cui, H.; Zhao, Y.; Li, J.; Wang, S. Metal Nitrate Catalysis for Selective Oxidation of 5Hydroxymethylfurfural into 2,5-Diformylfuran under Oxygen Atmosphere. ACS Omega 2019, 4, 7054-7060. [CrossRef] [PubMed]

184. Partenheimer, W.; Grushin, V.V. Synthesis of 2,5-Diformylfuran and Furan-2,5-Dicarboxylic Acid by Catalytic Air-Oxidation of 5-Hydroxymethylfurfural. Unexpectedly Selective Aerobic Oxidation of Benzyl Alcohol to Benzaldehyde with Metal/Bromide Catalysts. Adv. Synth. Catal. 2001, 343, 102-111. [CrossRef]

185. Saha, B.; Dutta, S.; Abu-Omar, M.M. Aerobic Oxidation of 5-Hydroxylmethylfurfural with Homogeneous and Nanoparticulate Catalysts. Catal. Sci. Technol. 2012, 2, 79-81. [CrossRef]

186. Amarasekara, A.S.; Green, D.; McMillan, E. Efficient Oxidation of 5-Hydroxymethylfurfural to 2,5-Diformylfuran Using Mn(III)Salen Catalysts. Catal. Commun. 2008, 9, 286-288. [CrossRef]

187. Hansen, T.S.; Sádaba, I.; García-Suárez, E.J.; Riisager, A. Cu Catalyzed Oxidation of 5-Hydroxymethylfurfural to 2,5-Diformylfuran and 2,5-Furandicarboxylic Acid under Benign Reaction Conditions. Appl. Catal. A Gen. 2013, 456, 44-50. [CrossRef]

188. Song, S.; Wu, G.; Guan, N.; Li, L. Upgrading of Biomass-Derived Furans into Value-Added Chemicals. In Production of Biofuels and Chemicals with Bifunctional Catalysts; Fang, Z., Smith, R.L., Li, H., Eds.; Biofuels and Biorefineries; Springer: Singapore, 2017; Volume 8, pp. 273-303, ISBN 978-981-10-5136-4.

189. Du, Z.; Ma, J.; Wang, F.; Liu, J.; Xu, J. Oxidation of 5-Hydroxymethylfurfural to Maleic Anhydride with Molecular Oxygen. Green Chem. 2011, 13, 554. [CrossRef]

190. Guo, H.; Yin, G. Catalytic Aerobic Oxidation of Renewable Furfural with Phosphomolybdic Acid Catalyst: An Alternative Route to Maleic Acid. J. Phys. Chem. C 2011, 115, 17516-17522. [CrossRef]

191. Langeslay, R.R.; Kaphan, D.M.; Marshall, C.L.; Stair, P.C.; Sattelberger, A.P.; Delferro, M. Catalytic Applications of Vanadium: A Mechanistic Perspective. Chem. Rev. 2019, 119, 2128-2191. [CrossRef] [PubMed]

192. Wojcieszak, R.; Santarelli, F.; Paul, S.; Dumeignil, F.; Cavani, F.; Gonçalves, R.V. Recent Developments in Maleic Acid Synthesis from Bio-Based Chemicals. Sustain. Chem Process. 2015, 3, 9. [CrossRef]

193. Li, H.; Guo, H.; Su, Y.; Hiraga, Y.; Fang, Z.; Hensen, E.J.M.; Watanabe, M.; Smith, R.L. N-Formyl-Stabilizing Quasi-Catalytic Species Afford Rapid and Selective Solvent-Free Amination of Biomass-Derived Feedstocks. Nat. Commun. 2019, 10, 699. [CrossRef]

194. Petri, A.; Masia, G.; Piccolo, O. Biocatalytic Conversion of 5-Hydroxymethylfurfural: Synthesis of 2,5-Bis(Hydroxymethyl)Furan and 5-(Hydroxymethyl)Furfurylamine. Catal. Commun. 2018, 114, 15-18. [CrossRef]

195. Feriani, A.; Gaviraghi, G.; Toson, G.; Mor, M.; Barbieri, A.; Grana, E.; Boselli, C.; Guarneri, M.; Simoni, D.; Manfredini, S. Cholinergic Agents Structurally Related to Furtrethonium. 2. Synthesis and Antimuscarinic Activity of a Series of N-[5-[(1'Substituted-Acetoxy)Methyl]-2-Furfuryl]Dialkylamines. J. Med. Chem. 1994, 37, 4278-4287. [CrossRef] 
196. Froidevaux, V.; Negrell, C.; Caillol, S.; Pascault, J.-P.; Boutevin, B. Biobased Amines: From Synthesis to Polymers; Present and Future. Chem. Rev. 2016, 116, 14181-14224. [CrossRef] [PubMed]

197. Cukalovic, A.; Stevens, C.V. Production of Biobased HMF Derivatives by Reductive Amination. Green Chem. 2010, $12,1201$. [CrossRef]

198. Nuzhdin, A.L.; Bukhtiyarova, M.V.; Bukhtiyarov, V.I. Two-Step One-Pot Reductive Amination of Furanic Aldehydes Using CuAlOx Catalyst in a Flow Reactor. Molecules 2020, 25, 4771. [CrossRef] [PubMed]

199. Xu, Z.; Yan, P.; Xu, W.; Jia, S.; Xia, Z.; Chung, B.; Zhang, Z.C. Direct Reductive Amination of 5-Hydroxymethylfurfural with Primary/Secondary Amines via Ru-Complex Catalyzed Hydrogenation. RSC Adv. 2014, 4, 59083-59087. [CrossRef]

200. Pingen, D.; Schwaderer, J.B.; Walter, J.; Wen, J.; Murray, G.; Vogt, D.; Mecking, S. Diamines for Polymer Materials via Direct Amination of Lipid- and Lignocellulose-Based Alcohols with $\mathrm{NH}_{3}$. ChemCatChem 2018, 10, 3027-3033. [CrossRef]

201. Xu, Z.; Yan, P.; Liu, K.; Wan, L.; Xu, W.; Li, H.; Liu, X.; Zhang, Z.C. Synthesis of Bis(Hydroxylmethylfurfuryl)Amine Monomers from 5-Hydroxymethylfurfural. ChemSusChem 2016, 9, 1255-1258. [CrossRef]

202. He, J.; Chen, L.; Liu, S.; Song, K.; Yang, S.; Riisager, A. Sustainable Access to Renewable N-Containing Chemicals from Reductive Amination of Biomass-Derived Platform Compounds. Green Chem. 2020, 22, 6714-6747. [CrossRef]

203. Senthamarai, T.; Murugesan, K.; Schneidewind, J.; Kalevaru, N.V.; Baumann, W.; Neumann, H.; Kamer, P.C.J.; Beller, M.; Jagadeesh, R.V. Simple Ruthenium-Catalyzed Reductive Amination Enables the Synthesis of a Broad Range of Primary Amines. Nat. Commun. 2018, 9, 4123. [CrossRef]

204. Pinheiro, D.; Nielsen, M. Base-Free Synthesis of Furfurylamines from Biomass Furans Using Ru Pincer Complexes. Catalysts 2021, 11, 558. [CrossRef]

205. Koh, P.-F.; Wang, P.; Huang, J.-M.; Loh, T.-P. Biomass Derived Furfural-Based Facile Synthesis of Protected (2S)-Phenyl-3Piperidone, a Common Intermediate for Many Drugs. Chem. Commun. 2014, 50, 8324-8327. [CrossRef]

206. Hazra, C.K.; Gandhamsetty, N.; Park, S.; Chang, S. Borane Catalysed Ring Opening and Closing Cascades of Furans Leading to Silicon Functionalized Synthetic Intermediates. Nat. Commun. 2016, 7, 13431. [CrossRef] [PubMed]

207. Dong, J.; Du, H.; Xu, J. Regiospecific Synthesis of Polysubstituted Furans with Mono- to Tricarboxylates from Various Sulfonium Acylmethylides and Acetylenic Esters. RSC Adv. 2019, 9, 25034-25038. [CrossRef]

208. Papadogianakis, G.; Maat, L.; Sheldon, R.A. Catalytic Conversions in Water: A Novel Carbonylation Reaction Catalysed by Palladium Trisulfonated Triphenylphosphine Complexes. J. Chem. Soc. Chem. Commun. 1994, 2659-2660. [CrossRef]

209. Geilen, F.M.A.; vom Stein, T.; Engendahl, B.; Winterle, S.; Liauw, M.A.; Klankermayer, J.; Leitner, W. Highly Selective Decarbonylation of 5-(Hydroxymethyl)Furfural in the Presence of Compressed Carbon Dioxide. Angew. Chem. Int. Ed. 2011, 50, 6831-6834. [CrossRef]

210. Li, X.; Sun, J.; Shao, S.; Hu, X.; Cai, Y. Aldol Condensation/Hydrogenation for Jet Fuel from Biomass-Derived Ketone Platform Compound in One Pot. Fuel Process. Technol. 2021, 215, 106768. [CrossRef]

211. Wu, L.; Moteki, T.; Gokhale, A.A.; Flaherty, D.W.; Toste, F.D. Production of Fuels and Chemicals from Biomass: Condensation Reactions and Beyond. Chem 2016, 1, 32-58. [CrossRef]

212. Ramírez, E.; Soto, R.; Bringué, R.; Iborra, M.; Tejero, J. Catalytic Hydroxyalkylation/Alkylation of 2-Methylfuran with Butanal to Form a Biodiesel Precursor Using Acidic Ion-Exchange Resins. Ind. Eng. Chem. Res. 2020, 59, 20676-20685. [CrossRef]

213. Nie, G.; Zhang, X.; Pan, L.; Wang, M.; Zou, J.-J. One-Pot Production of Branched Decalins as High-Density Jet Fuel from Monocyclic Alkanes and Alcohols. Chem. Eng. Sci. 2018, 180, 64-69. [CrossRef]

214. Anbu, N.; Maheswari, R.; Elamathi, V.; Varalakshmi, P.; Dhakshinamoorthy, A. Chitosan as a Biodegradable Heterogeneous Catalyst for Knoevenagel Condensation between Benzaldehydes and Cyanoacetamide. Catal. Commun. 2020, $138,105954$. [CrossRef]

215. Liu, D.; Chen, E.Y.-X. Integrated Catalytic Process for Biomass Conversion and Upgrading to $C_{12}$ Furoin and Alkane Fuel. ACS Catal. 2014, 4, 1302-1310. [CrossRef]

216. Tao, L.; Yan, T.-H.; Li, W.; Zhao, Y.; Zhang, Q.; Liu, Y.-M.; Wright, M.M.; Li, Z.-H.; He, H.-Y.; Cao, Y. Toward an Integrated Conversion of 5-Hydroxymethylfurfural and Ethylene for the Production of Renewable p-Xylene. Chem 2018, 4, $2212-2227$. [CrossRef]

217. Kabro, A.; Escudero-Adán, E.C.; Grushin, V.V.; van Leeuwen, P.W.N.M. Biomass Conversion to High Value Chemicals: From Furfural to Chiral Hydrofuroins in Two Steps. Org. Lett. 2012, 14, 4014-4017. [CrossRef] [PubMed]

218. Li, H.; Xu, Z.; Yan, P.; Zhang, Z.C. A Catalytic Aldol Condensation System Enables One Pot Conversion of Biomass Saccharides to Biofuel Intermediates. Green Chem. 2017, 19, 1751-1756. [CrossRef]

219. Sharma, U.K.; Gemoets, H.P.L.; Schröder, F.; Noël, T.; Van der Eycken, E.V. Merger of Visible-Light Photoredox Catalysis and C-H Activation for the Room-Temperature C-2 Acylation of Indoles in Batch and Flow. ACS Catal. 2017, 7, 3818-3823. [CrossRef]

220. Ebru Aydin, A.; Yuksekdanaci, S. Asymmetric Henry Reactions Catalyzed by Metal Complexes of Chiral Oxazoline Based Ligands. Tetrahedron Asymmetry 2013, 24, 14-22. [CrossRef]

221. Böhm, C.; Schinnerl, M.; Bubert, C.; Zabel, M.; Labahn, T.; Parisini, E.; Reiser, O. A new strategy for the stereoselective synthesis of 1,2,3-trisubstituted cyclopropanes. Eur. J. Org. Chem. 2000, 2000, 2955-2965. [CrossRef]

222. Asano, R.; Moritani, I.; Fujiwara, Y.; Teranishi, S. Aromatic Substitution of Olefins. XIX. Reaction of Five-Membered Heterocyclic Aromatic Compounds with Styrene. BCSJ 1973, 46, 663-664. [CrossRef] 
223. Sevov, C.S.; Hartwig, J.F. Iridium-Catalyzed Oxidative Olefination of Furans with Unactivated Alkenes. J. Am. Chem. Soc. 2014, 136, 10625-10631. [CrossRef]

224. Majer, J.; Kwiatkowski, P.; Jurczak, J. Highly Enantioselective Synthesis of 2-Furanyl-Hydroxyacetates from Furans via the Friedel-Crafts Reaction. Org. Lett. 2008, 10, 2955-2958. [CrossRef] [PubMed]

225. Yamazaki, S.; Kashima, S.; Kuriyama, T.; Iwata, Y.; Morimoto, T.; Kakiuchi, K. Enantioselective Friedel-Crafts Reactions of Ethenetricarboxylates and Substituted Pyrroles and Furans and Intramolecular Reaction of Benzene Derivatives. Tetrahedron Asymmetry 2009, 20, 1224-1234. [CrossRef]

226. Chacón-Huete, F.; Mangel, D.; Ali, M.; Sudano, A.; Forgione, P. High-Value Biomass-Derived 2,5-Furandicarboxylic Acid Derivatives Obtained by a Double Decarboxylative Cross-Coupling. ACS Sustain. Chem. Eng. 2017, 5, 7071-7076. [CrossRef]

227. Chacón-Huete, F.; Lasso, J.D.; Szavay, P.; Covone, J.; Forgione, P. Synthesis of 2,5-Diaryl Nonsymmetric Furans C6-Platform Chemicals via Catalytic Conversion of Biomass and the Formal Synthesis of Dantrolene. J. Org. Chem. 2021, 86, 515-524. [CrossRef] [PubMed]

228. Masuda, T. Substituted Polyacetylenes: Synthesis, Properties, and Functions. Polym. Rev. 2017, 57, 1-14. [CrossRef]

229. Romashov, L.V.; Ananikov, V.P. Alkynylation of Bio-Based 5-Hydroxymethylfurfural to Connect Biomass Processing with Conjugated Polymers and Furanic Pharmaceuticals. Chem. Asian J. 2017, 12, 2652-2655. [CrossRef] [PubMed] 